\title{
Building policy scales from manifesto data: A referential content validity approach
}

DOI:

10.1016/j.electstud.2014.05.004

Document Version

Accepted author manuscript

Link to publication record in Manchester Research Explorer

\section{Citation for published version (APA):}

Prosser, C. (2014). Building policy scales from manifesto data: A referential content validity approach. Electoral Studies, 35, 88-101. https://doi.org/10.1016/j.electstud.2014.05.004

\section{Published in:}

Electoral Studies

\section{Citing this paper}

Please note that where the full-text provided on Manchester Research Explorer is the Author Accepted Manuscript or Proof version this may differ from the final Published version. If citing, it is advised that you check and use the publisher's definitive version.

\section{General rights}

Copyright and moral rights for the publications made accessible in the Research Explorer are retained by the authors and/or other copyright owners and it is a condition of accessing publications that users recognise and abide by the legal requirements associated with these rights.

\section{Takedown policy}

If you believe that this document breaches copyright please refer to the University of Manchester's Takedown Procedures [http://man.ac.uk/04Y6Bo] or contact uml.scholarlycommunications@manchester.ac.uk providing relevant details, so we can investigate your claim.

\section{OPEN ACCESS}




\title{
Building policy scales from manifesto data

\author{
A referential content validity approach
}

\author{
Christopher Prosser \\ University of Manchester ${ }^{1}$ \\ chris.prosser@manchester.ac.uk
}

Electoral Studies, 35, pp 88-101, 2014.

\begin{abstract}
Researchers using scales based on MRG/CMP/MARPOR's manifesto dataset face a bewildering array of different scales. The validation of these scales has tended to focus on external, convergent validity. The actual content of these scales has received less attention and the choice of the manifesto components which make up these scales has often been conducted by either opaque or questionable methods. This article develops a critique of existing methods of component selection and proposes a new method of component selection based on the covariance of components with 'naïve' provisional scales, which are refined in an iterative process. It uses this method to construct a set of comparable one (general left-right) and two (economic and social) dimensional scales - filling a gap in the existing body of scales that will allow researchers to compare dimensionality across models without inadvertently comparing different assumptions that underlie the construction of the scales.
\end{abstract}

\footnotetext{
${ }^{1}$ At the time of publication, St Catherine's College, University of Oxford
} 
Determining where a party sits on a policy issue or an ideological dimension is one of the most fundamental questions of measurement in political science. Whether the end research goal is one of how parties' positions influence electoral choices, intergovernmental negotiations, or budget overruns (to name but a tiny fraction of the ways party positions have been used in the literature), scholars must first determine what the relevant policy dimensions are, and then, where parties sit on them. There have been myriad answers to these basic questions which broadly draw on four methodological approaches - expert surveys, mass surveys, roll call votes, and electoral manifesto data. All of these approaches have their benefits and costs, and in an ideal world, many approaches would be used to ensure cross-validation of empirical findings. Unfortunately however, the world is far from ideal, particularly if we wish to analyse politics across a wide time span: we cannot travel back in time and conduct expert and mass surveys, and the existing surveys do not cover a long enough periods nor are they conducted at regular enough intervals to track fine grained developments in multiple countries. Scholars who wish to tackle these questions currently only have one option, to use manifesto data, specifically that collected by the group currently known as the Manifesto Project on Political Representation (MARPOR) (Budge et al., 2001; Klingemann et al., 2006; Volkens et al., 2009). ${ }^{2}$

Although a certain amount of methodological handwringing seems to be de rigueur amongst scholars who use them, the general validity of scales derived from MARPOR data has now been well established. MARPOR have endeavoured to show the validity of manifesto scales - particularly their 'Rile' scale - across many different validity criteria (Budge et al., 2001; Klingemann et al., 2006). Many authors however, particularly critics of MARPOR's scaling methods, have tended to focus only on convergent validity, tested by cross validation with scales derived from other techniques (Bakker

\footnotetext{
${ }^{2}$ Depending on the date, this group has alternatively been called the Manifesto Research Group (MRG), Comparative Manifesto Project (CMP), or most recently, the Manifesto Project on Political Representation (MARPOR). MARPOR is used as a generic term to cover all of the incarnations of the project.
} 
and Hobolt, 2013; Budge, 2001; Budge et al., 2001; Klingemann et al., 2006; Lowe et al., 2011; Ray, 2007).

Although a bewildering number of scales have been constructed from MARPOR data, their convergent validity is often tested against the same expert survey data - most commonly the Laver and Hunt/Benoit and Laver and Chapel Hill group expert surveys (Benoit and Laver, 2007; Hooghe et al., 2010; Laver and Hunt, 1992; Steenbergen and Marks, 2007). Although some authors seem to treat them as such in their validation approaches, expert surveys do not represent 'true' party positions, but rather estimates of these positions with their own strengths and weaknesses (Budge, 2000; Steenbergen and Marks, 2007; Volkens, 2007), and so their use in discriminating against competing manifesto scales is problematic. Even leaving these debates to one side, the fact that many different scales, composed of different manifesto components and combined by different methods, all apparently perform equally well in terms of convergent validity suggests that although cross-validation is an essential method of establishing the general validity of different scales, it is perhaps less useful as a technique for choosing between them.

That different scales have been found to have essentially equal convergent validity is not completely surprising given the large overlap in the components used to construct them, as demonstrated by the three examples of 'left-right' scales shown in table 1, and the two 'social' scales shown in table 2. That each of these scales has been cross-validated suggests that scholars must turn to other measures of validity in order to choose between them.

[table 1 about here]

[table 2 about here]

Researchers interested in questions relating to the dimensionality of politics also face another concern - the various sets of scales on offer tend to treat the underlying dimensionality of politics as either unidimensional or multidimensional. MARPOR's Rile scale implies a single 'super dimension' ranging from liberal/state control of the economy/left to conservative/free market/right. Many 
other manifesto scales approaches have also adopted a one-dimensional approach (Franzmann and Kaiser, 2006; Gabel and Huber, 2000). One dimensional scales are prevalent in many streams of the political science literature, and not only when using scales from manifesto data. However, whenever scholars set out to look for multiple ideological dimensions, they tend to find them (Bakker et al., 2012; Henjak, 2010; Schofield, 1993; Stoll, 2010a; Warwick, 2002).

Although the descriptions given to these dimensions varies from scholar to scholar a consistent finding has been the existence of an economic dimension, consisting of issues surrounding markets, labour, economic planning and regulation, and a social dimension, consisting of issues surrounding personal freedoms, human rights, morality, and traditions. ${ }^{3}$

Although the existing evidence supports a multidimensional interpretation of political space, the approach here remains agnostic to this question and recognises that the use of one or two dimensions in research may be driven by many reasons - from the appropriateness of multiple dimensions in different contexts to simple matters of pragmatisms surrounding the availability of other data with which researchers wish to compare their data (left-right placements in survey research tend to be unidimensional for example).

On some questions, rather than taking an a priori stance on the question of dimensionality, scholars may wish to compare the results of alternately specifying uni- or multidimensional models investigating party competition - for example whether party positions on a particular policy are best explained by a one or two dimensional conception of political space. A problem facing such research questions is that scales using the MARPOR data have tended to be developed using either a uni- or multidimensional framework and there is no one set of scales that contains both uni- and multidimensional scales that shares an underlying method of component choice. MARPOR's venerable 'Rile' scale may well be appropriate for a unidimensional approach, or the Benoit and

\footnotetext{
${ }^{3}$ Common names for the economic dimension include 'left-right', and 'materialist'. Common names for the social dimension are 'liberal-conservative', 'libertarian-authoritarian, 'post-materialist', 'Green/Alternative/Libertarian-Traditional/Authoritarian/Nationalist'. Here they will be called the 'Economic Left-Right', and 'Social Liberal-Conservative' dimensions.
} 
Laver (2007) state intervention in the economy and social liberal-conservative scales for a multidimensional approach, but comparing the Rile scale to the Benoit and laver scales engenders not just a comparison of dimensionality, but also of different underlying assumptions about which component should be included and excluded in a scale. The results of any analysis based on such a comparison may occur not as a result of any true underlying relationship but because of different decisions about which components should be included or excluded from a scale. The aim of the present article is to produce a set of one and two dimensional scales that are uniquely comparable across conceptions of dimensionality because they are based on the same assumptions and selection method, though each scale is of course suitable for standalone use as well.

Any scholar wishing to develop MARPOR scales faces three questions: What components should be used to construct the scale? How should they be combined? Are the scales valid measures of what they are supposed to measure? Although these questions suggest a natural order of enquiry, the existing literature has most satisfactorily answered them in reverse. As has already been discussed the general validity of MARPOR scales is now well established. Similarly, several different methods of combining components have been developed and assessed (Kim and Fording, 1998; Lowe et al., 2011; Ray, 2007). However existing approaches to component selection - or in other words, the content validity of scales - are less well developed and are often conducted on an ad hoc basis. This article argues that scholars should think carefully about the ways in which different methods of counting manifesto components affect the end result of the scale, and how individual components should relate to the overall scale. It then develops a novel method for selecting components based on their exogenous correlation with provisional overall scales and uses it to construct a set of new scales.

\section{Building Blocks}


The MARPOR dataset consists of observations of political parties at particular elections. ${ }^{4} \mathrm{~A}$ political document (usually the party's electoral manifesto, though occasionally other documents are substituted) is coded by counting the number of 'quasi-sentences' that fit in 56 predefined categories. ${ }^{5}$ MARPOR report the salience of each category in a manifesto as a percentage of the total number of quasi-sentences in the manifesto. Although each component is a measure of salience, MARPOR (and every subsequent measure) use combinations of categories to create positional measures. The general logic behind converting salience measures to positional measures being that the more a party emphasises 'left' or 'right' issues (salience) the more 'left' or 'right' (in terms of position) we can consider it to be.

The percentage measure is the most commonly used starting point for scale building, including the MARPOR's own 'Rile' scale. As the building block of positional scales however, it has one main problem in that it is not independent of irrelevant alternatives (IIA): the value assigned to a specific number of quasi-sentences changes with the inclusion of other additional, irrelevant, quasisentences. To demonstrate how this problem might adversely affect the outcome of positional scales take the case of an imaginary political party at two elections. The political party (being lazy) copies its entire manifesto from the first election and uses it again - word for word - at the second, with the addition of one superficial and (from a policy perspective) irrelevant sentence congratulating a national sporting team on their success at the recent Olympics. ${ }^{6}$ Despite having identical policies in both manifestos the total number of quasi-sentences in the two manifestos will

\footnotetext{
${ }^{4}$ The analysis here is conducted on the full $2012 \mathrm{~b}$ version of the MARPOR dataset (the latest at time of analysis), which contains 3,611 country-election-party observations from 614 elections in 55 countries.

${ }^{5}$ The analysis here does not include the additional subcategories that were later added to the original coding scheme for manifestos from former Soviet countries (per1011 - per7062) as they are not used in all countries.

${ }^{6}$ It could perhaps be argued that even this is not actually an 'irrelevant' issue for some reason, but this case is simply meant to illustrate the IIA argument with a trivial example rather than the irrelevancy of this particular case.

The MARPOR position on this issue is that manifestos are created by political parties in a meticulously thought through, carefully negotiated, and thoroughly deliberate process and so we should take all policy statements as 'intended'. How this affects the IIA argument depends in part on the purpose of a scale. If the scale is intended as a summary measure of an entire manifesto as a whole (which is one role of the RILE scale) then the IIA problem may not be an issue. If a scale is intended only as a measure of a specific policy dimension then not all statements will actually be relevant and so the IIA problem holds.
} 
be different and so each category will receive different percentage scores in each of the quasisentence categories and consequently, regardless of the method used to combine the information, will receive slightly different positions on a policy scale.

The IIA issue is potentially particularly problematic when building scales in a multidimensional setting. The percentage salience of components used in one scale will be affected not just by irrelevant information but by information that is relevant to other scales, leading to potential endogeneity problems. As parties emphasise issues on a particular dimension then the relative salience of others will decrease, leading to positions that are closer to the centre of the scale than would otherwise be the case.

One obvious alternative is simply to substitute the total number of quasi-sentences in each category for the percentage measure. However depending on the combination method used, this is also potentially problematic because the overall length of manifesto varies considerably between different parties. The data suggests that the different lengths are not randomly dispersed between countries and parties either: the mean number of total quasi-sentences varies considerably by country - for example Spain (mean length $=1493.64$, standard deviation $=1230.82$ ) has manifestos that are on average 10 times the size of those found in Denmark (mean length $=126.14$, standard deviation $=124.31)$. Manifestos also vary considerably depending on the type of party writing them - on average Green parties (mean length $=732.17$, standard deviation $=959.15$ ) write manifestos that are about 200 quasi sentences longer than any other party family. Whether this is a problem depends on the method used to combine the components to form a scale. Specific methods will be discussed in more detail below but in general components are combined by one of two methods additive scales, and ratio scales. Both methods assign different components to a 'side' of a policy spectrum, additive scales subtract the total number of components on one side from the total components on the other, whilst ratio scales use a ratio of the additive scale to the total number of components used to construct it. Unless a party's manifesto is particularly balanced between issues 
on either side of a policy scale, using the raw number of quasi-sentences to create additive scales will lead to more extreme positions on a scale (and a much bigger scale) and uncertain comparability of scores between parties. Again the significance of this is perhaps most easily shown with a hypothetical example.

Imagine two parties that are generally left-wing on economic issues. Both have similar positions and spend $80 \%$ of their manifesto discussing the merits of government intervention in the economy and $20 \%$ discussing the positive aspects of free markets. Using the percentage quasi-sentence measure in a simple additive fashion gives them both the same score of -60 (on a -100 to 100 scale). Now imagine that the parties have manifestos of very different lengths, the first is a Danish party and conforms to the Danish average and has a manifesto of 126 quasi-sentences (with some rounding 101 quasi-sentences on the left of the scale and 25 on the right), whilst the other party is Spanish, with a manifesto 1494 quasi-sentences long (1195 left quasi-sentences and 299 right). Using additive scales the Danish party has a score of -76 and the Spanish party has a score of -896 (on a scale that stretches to infinity in either direction). Are these scores in any way meaningful? Is the Spanish party really more than 11 times more left wing than the Danish party simply because they are more verbose? The obvious answer to both questions is no. This example, although deliberately concocted to give an absurd result, clearly illustrates the problem of using additive scales with the raw number of sentences.

The same problem does not exist for ratio scales. The simplest and most commonly used version of the ratio scale was developed by Kim and Fording (1998). To show how ratio scales cope with different sized manifestos a slightly modified (to keep 'left' values as negative numbers) version of the Kim-Fording formula is used to calculate scores for the two example parties:

$$
\theta^{R}=\frac{\text { Right wing quasi }- \text { sentences }- \text { Left wing quasi }- \text { sentences }}{\text { Right wing quasi }- \text { sentences }+ \text { Left wing quasi }- \text { sentences }}
$$


Using the percentage values the score for both parties is -0.6 (on a -1 to 1 scale), whilst using the raw quasi-sentences yields -0.603 and -0.599 for the Danish and Spanish example parties respectively (the small differences due to earlier rounding).

The above discussion gives an early indication of how a desirable scale that takes into account the IIA problem might be constructed - using some sort of ratio measure with the raw quasi-sentence data. However using the ratio method in the way established by Kim and Fording has some serious drawbacks. When a manifesto only has quasi-sentences on one side of the policy scale, regardless of the number of quasi-sentences used to describe a policy it will equal 1 or -1 . If this is the case a ratio scale cannot distinguish between a single sentence placatory statement and a 100 sentence ode of praise - a key feature in the logic of building positional scales from salience data. This is not just a theoretical problem, in practice, when the number of components included in a scale is small it leads to overly polarised scales, as demonstrated in figure 1 , which shows the distribution of a Kim-Fording ratio scale using the components of the Benoit and Laver (2007) 'social liberal-conservative' scale (as shown in table 1).

[figure 1 about here]

More recently Lowe et al. (2011) developed what they call a 'logit' scale for MARPOR data using the raw number of quasi-sentences in manifesto components. The logit scale is calculated using the formula:

$$
\theta^{L}=\log \frac{R+0.5}{L+0.5}
$$

Where $R$ is the total number of quasi-sentences in the manifesto components on the 'right' of the scale and $L$ is the total number of quasi-sentences in the manifesto components on the 'left'.

The Lowe et al. logit scale has several desirable features: The nature of logarithms means that to some extent the logit scale can be considered to be both an additive scale and a ratio scale $\left(\log \frac{a}{b}=\right.$ 
$\log a-\log b)$. By using the raw number of quasi-sentences rather than the percentage measure to construct the scale it avoids the IIA problem and by using a ratio approach it avoids the problem of different manifesto sizes. Additionally Lowe et al. modify the general logic of the salience approach to positional scaling - although they still agree that additional mentions of 'right' or 'left' components shift a party's position on a positional scale, drawing on well established findings from psychophysics they argue that each additional mention of an issue is of diminishing importance compared to previous mentions (an argument which suggests the use of a logarithm): a shift from zero to one quasi-sentence mentions of support for the welfare state should make more of a difference to the policy position than a shift from 99 to 100 . As well as a better fit with natural usage of emphasis and scales, the logit scale has the additional advantage in that it solves the problem of polarised scales found in the Kim-Fording ratio scale, as the distribution of the Benoit and Laver (2007) 'social liberal-conservative' scale calculated using the logit scale method shows in figure 1.

A third general approach to manifesto scale building are a variety of methods which 'derive' their scales from the data, for example by using factor analysis, multidimensional scaling, or maximum likelihood estimation (Elff, 2013; Gabel and Huber, 2000; König et al., 2013). Putting aside problems of variable selection that these methods face (which will be discussed in detail below), any derivative scaling method necessarily breaks a second type of IIA because it is dependent on the sample used by the researcher to calculate it - whether by conscious decision or the availability of data at the time: the estimated position of a party at time one will depend on whether or not the party is also measured at time two. Whether this is a problem is a decision for individual researchers - for isolated projects this IIA problem may not be an issue. However if the goal is to generate a scale that can be used for future research without having to recalculate a scale each time it is needed, with uncertain comparability to previous research (as it is here) then derivative scales are of no use. Additionally, unless the scale is derived from the entire manifesto dataset - as is the case in the Gabel and Huber (2000) approach - then some prior selection of components is still necessary, and so many of the potential pitfalls of component selection which affect non-derived scales still apply. 


\section{Component selection: existing approaches}

Due to its robustness to IIA problems whilst still retaining the central feature of salience effects on party positioning the logit scaling method proposed by Lowe et al. (2011) provides the most appropriate method of scale calculation for the purposes of the present analysis. ${ }^{7}$ It is yet to be established however which components should actually be used to calculate the scales. Component selection methods can be broadly divided into two categories: deductive and inductive methods.

The deductive method of component selection describes a process in which a researcher selects, $a$ priori, the components which they think belong in scale. The assumptions a researcher makes are sometimes explicit, such as the original MARPOR 'Rile' scale, which is based on a conceptualisation of political ideology at the turn of the $20^{\text {th }}$ century or Jahn's (2011) use of the political philosopher Norberto Bobbio's conceptualisation of left and right. Often though the a priori assumptions researchers make are implicit, Benoit and Laver for example, justify their component selection using 'common-sense substantive judgements' (2007, p. 100). Their selection is then confirmed by $a$ posteriori cross validation with other scales. Occasionally the deductive selection of components is simply presented as a fait accompli without further justification (König and Luig, 2012; Stoll, 2010b). For some purposes deductive scales may be perfectly suitable - there are valid questions which require measuring how well parties fit to predefined criteria. If however the purpose of the scale is to try and measure the underlying dimensionality of politics, the obvious potential problem with deductive methods is that the assumptions they make about how components relate to each other might be wrong.

In a discussion of the issues facing researchers interested in dimensionality, Benoit and Laver (2012, p. 216) argue that

\footnotetext{
${ }^{7}$ Although I stand by the arguments given here, those who are not convinced by the logit scales (as the core MARPOR team remain to be) or using the raw number of quasi-sentences instead of the percentage salience measure should take note that the method of component selection developed here could equally be carried out using any other type of salience measure or combination method.
} 
'Just as physical maps are spanned by physical dimensions, conceptual maps are spanned by conceptual dimensions, which we use to provide substantive orientation. Just as there is not one true map, neither is there 'one true dimensionality' for any given political setting. Sometimes, as with London's Central Line, a one-dimensional map will tell us everything we want to know. Sometimes, as with London's Circle Line, it will not. Nearly always, we ignore potentially salient dimensions in the name of a parsimonious description of the world, just as we typically do not seek three-dimensional maps of London Tube stations - despite the fact that these stations do in fact have substantively meaningful geographical coordinates in three dimensions.'

The potential problems with deductive approaches to scale building are not the necessary assumptions of abstraction and reduction. To borrow Benoit and Laver's mapping metaphor, the problem is incorrect cartography - a major road is missing from a street map or where the map says there is a forest there is in fact a lake. That researchers may have been making similar errors in mapping policy dimensions is readily apparent from comparison between different scales. Compare for example, the two social dimension scales presented in table 2 which both claim to measure a similar dimension: the two scales each use component 201 - 'positive mentions of freedom and human rights' on different sides of the scale.

How do we know which of these choices is correct? The orthodox approach is to cross validate the scales with other sources of scale positions. That both the Benoit and Laver (2007) and Bakker and Hobolt (2013) scales have been cross validated using expert surveys is a good indication that this approach is ineffective for distinguishing between scales. The reason for this lies in the fact that with a sufficient number of components, the general shape of scales is remarkably robust to omitted and miscoded components. That this is the case is most easily illustrated by doing so deliberately, using the components of the Rile scale (table 1) calculated using the logit method. Compared to the full scale, removing four 'social' variables from the scale (201 - Freedom and Human Rights, 203 - 
Constitutionalism, 106 - Peace, and 107 - Internationalism) the two scales are still very well correlated (0.9459) and have a Cronbach's alpha value equating to 'excellent' internal consistency between the scales (0.9687). ${ }^{8}$ Removing an additional four 'economic' variables (402 - Incentives, 407 - Protectionism: Negative, 412 - Controlled Economy, and 413 - Nationalisation) leads to a correlation of 0.9225 with the full scale and actually increases the Cronbach's alpha to 0.9512. Even dropping a further four components (305 - Political Authority, 505 - Welfare State Limitation, 105 Military: negative, and 403 - Market Regulation) so that only 14 of the original 26 components are left in the scale leads to a correlation of 0.8366 and a Cronbach's alpha over the 'excellent' threshold: 0.9016 .

The same pattern can be shown when deliberately coding components on the wrong side of a policy divide. Compared to the 'correct' scale, a scale with component 401 - Free Enterprise swapped to the 'left' of the scale has a correlation of 0.9472 and a Cronbach's alpha of 0.9712 . Swapping componet 413 - Nationalisation (in addition to 401), gives a correlation of 0.9245 and a Cronbach's alpha of 0.9557. Swapping component 504 - Welfare State Expansion (again in addition to 401 and 413), drops the correlation to 0.7187 , but still gives a 'good' Cronbach's alpha of 0.8211 . Finally swapping component 414 - Economic Orthodoxy, so that there are now four components on the 'wrong' side, drops the correlation to 0.5693 , but still yields an 'acceptable' Cronbach's alpha of 0.7077 .

These examples, which include components which are by no means trivial to our understanding of 'left' and 'right', show the limitations of the cross validation method of justifying component selection - scales can be broadly 'correct' whilst missing important components, including erroneous ones, and coding components on the 'wrong' side. ${ }^{9}$

\footnotetext{
${ }^{8}$ Commonly used interpretations of Cronbach's alpha are scores over 0.7 are considered 'acceptable', those over 0.8 are 'good', and those over 0.9 are 'excellent'.

${ }^{9}$ The general robustness of manifesto scales to miscoding should also reassure the reader about the general validity of previous research based on manifesto scales. The point of the discussion here is not to 'invalidate'
} 
Rather than face the obvious problems of choosing scale components by a deductive process, some scholars have used inductive statistical tools, primarily principal component analysis and factor analysis, to select scale components (Bakker and Hobolt, 2013; Budge, 1987; Klingemann, 1995; Laver and Budge, 1992). Such techniques are also prone to the IIA problem discussed in relation to inductively derived scales - they are reliant on (at most) the current MARPOR dataset, which is ever expanding as more elections are held and manifestos coded. Inductively selecting components rather than deriving party positions means that party positions on the scale are themselves robust to the inclusion of future parties (unlike derived scales). However, the components selected to form the scale are not - a future dataset may yield different result for whichever inductive technique is chosen. A similar problem is of course true for deductively selected scales as well - although assumptions about how different issues related to underlying dimensions at any given time may be correct, politics changes and issues may lose or gain relevance over time. Ultimately there will never be any 'true' scale that will accurately map party positions across all times and places. The choice facing researches is how to best construct 'temporary' scales that will hopefully last for a reasonable length of time. Given the concerns about the fallibility of human reason and 'common sense' in choosing scale components, an inductive approach is chosen here.

A re-examination of previous devised scales with factor analysis is a very revealing exercise and suggests that it is not an appropriate method for choosing scale components. An exploratory factor analysis of the components used to make MARPOR's Rile scale reveals no fewer than 20 factors with Eigenvalues above the conventional cut-off point of 1, with the best factor only explaining $5.013 \%$ of the variance. Similar results are found for the Bakker and Hobolt (2013) scales. Their left right scale reveals 9 factors with eigenvalues above 1 and the best factor explaining $8.663 \%$ of the variance, and their libertarian-authoritarian scale reveals 6 factors, with the best explaining $11.059 \%$ of the variance.

previous scales, indeed the general validity of manifesto scales - despite any of problems discussed here - is the key starting point for the new scales developed here. 
The only way for factor analysis to reveal the number of dimensions commonly found in research (1 or 2) is if the dimensions are limited a priori. As Benoit and Laver (2012) discuss, there might be good reasons for doing so. The results of the exploratory factor analyses presented here however suggest that the resulting dimensions are not very coherent by the ordinary standards of factor analysis.

Why is this the case? The first problem with using factor analysis approaches is that they have tended to use conventional techniques, which were designed for use on interval data, rather than tools more appropriate to count data with many zero values (components with no quasi-sentence mentions), leading to serious calculation problems (Ridout et al., 1998; van der Broug, 2001; Wedel et al., 2003). Even if more appropriate tools were used however, the nature of the manifesto dataset presents a serious obstacle for any analysis by factor analysis.

A Kaiser-Meyer-Olkin (KMO) measure of sampling adequacy of the MARPOR dataset gives a value of 0.499 , just below 0.5 , the minimum standard indicating a matrix is suitable for factor analysis. The low KMO score is indicative of the fact that manifesto components are very poorly correlated with each other. Taking the components used in the Rile scale as an example - the overall mean correlation between components on the 'right' is 0.12 , whilst those on the 'left' is 0.11 . Even the 'best' correlation, between 105 - military: negative, and 406 - protectionism: positive, is only 0.437 . In short, unlike other common scales which use different measures of similar underlying factors (and when factor analysis is a more appropriate tool) the components used in manifesto scales simply do not co-vary in the same way and the logic behind combining them into a scale is different to that over ordinary scales that rely on multiple measurements of the same latent variable.

Similar manifesto components are, to a certain degree, substitutable, a logic which works at both the manifesto writing stage and the coding stage. Given a finite amount of space in a manifesto, parties will express their positions concisely - for example rather than two statements expressing support for orthodox economic practices and support for free enterprise they might combine their position into one statement. This is then compounded at the coding stage where statements are 
coded exclusively into one category. As the number of statements in some categories increases the space available for statements in other categories decreases. Components 105 and 406 (the two most highly correlated components used in the rile scale) is an excellent illustration of this comparing each component to a dummy variable indicating whether any mention of the other component is made reveals slightly negative correlations in both cases $(-0.0188$ for the 105 to 406 dummy and -0.0488 for the 406 to 105 dummy comparison) which indicates that the more a party mentioned one of the components the less likely they were to make any mention of the other. Although this is not true for all similar components (for example, parties making statements about welfare expansion [504] are also more likely to make statements about education expansion [506]) it is a good illustration of the complex relationship between scale components, and precisely why manifesto data does not lend itself to factor analysis.

\section{Component selection: a new approach}

Given the problems with existing methods of component selection in manifesto scales, it is clear that a new method is needed. In order to develop this method we must first ask a simple question: what is a policy scale supposed to do? To borrow Benoit and Laver's (2012) mapping metaphor, a policy scale gives people the ability to navigate the complex combination of myriad policy issues in a comprehensible fashion. When we say $x$ party is on the 'right' or 'left' we are asserting that it has particular positions on a broad range of issues, or in other words that certain issues tend to co-vary: parties on the economic 'right' tend to be in favour of both market deregulation and restrictions on trade unions; parties that are 'conservative' on the social dimension tend to be against gay marriage and limiting access to abortions.

That policy scales are heuristic devices that condense multiple issues into parsimonious measures is well established. Whether the issues included in existing scales are actually condensable is not. To use the more formal language of psychometrics: their content validity remains untested. In psychometrics the standard method of testing content validity is to ask a panel of experts and 
calculate a 'content validity ratio' (Lawshe, 1975). The method here, though testing the same criteria, takes a different approach. In basic terms, it measures the extent that individual components actually co-vary with the policy scale. That we can perform such tests - which necessarily initially rely on using at least partially 'invalid' scales based - is based on two already established properties:

The general validity of manifesto scales has been well established by tests of convergent validity. Manifesto scales are fairly robust to missing and miscoded components.

That existing scales can be considered broadly 'correct', even if there are some components which should be included or excluded but are not, allows them to be used as initial scales against which we can measure the covariance of individual components. That scales are robust to the exclusion of components which should be included also allows us to overcome an endogeneity problem: given the method by which scales are calculated we should expect a certain degree of correlation between a scale and any component that is included in it. That scales are robust to missing components allows us to test each component against a scale that does not include it in calculation. This then is the criteria by which components will be selected for inclusion or exclusion in a policy scale: the exogenous correlation between a component and the relevant policy scale.

\section{Measuring components}

In order to measure the exogenous correlation it is first necessary to decide how to measure the individual components. Unlike its use as the building block for the overall scale, the raw number of quasi-sentences in a component is not a good measure of the emphasis placed a component in a manifesto because, as has already been discussed, it varies considerably with the size of a manifesto. A measure of salience must take into account both the number of quasi-sentences in a particular component and the total number of sentences in a manifesto. 
Rather than use the original percentage salience measure, Lowe et al. (2011) argue that much like their logit scale measure, a logarithmic structure should be given to the salience measure because of the diminishing importance of subsequent mentions of a policy. Lowe et al. propose a measure calculated by the formula: ${ }^{10}$

$$
\theta^{I}=\log \frac{S+1}{N}
$$

Where $S$ is the number of sentences for each relevant variable in a manifesto and $N$ is the total number of sentences in a manifesto.

Although the implementation of a logarithmic approach is an innovative contribution to the question of how to measure salience in a manifesto, Lowe et al.'s specific measure has a serious flaw because it does not have a stable value for components that are not mentioned in a manifesto. As the total number of sentences in a manifesto increases the value assigned to components that are not mentioned (i.e. that have 0 quasi-sentences) decreases. How problematic this is depends on the task the researcher wishes to use the measure for: for comparing the importance of particular components within a single manifesto the measure is acceptable, but for comparing the importance of components across manifestos the flaw may introduce serious bias according to the lengths of the manifestos examined. The changing value for components not mentioned is particularly problematic when comparing small and large manifestos: not mentioning an issue at all in a small manifesto may score higher than mentioning an issue in several sentences in a large manifesto. For example: the zero score for a manifesto with 150 sentences is -5.01064 , whilst the score for an issue that is mentioned in five quasi sentences in a 1000 sentence manifesto is -5.116 .

However this problem is easily overcome by using a different formula that retains the logarithmic elements of Lowe et al.'s scale but has a stable value for no mentions:

\footnotetext{
${ }^{10}$ Lowe et al. use this formula to measure the emphasis placed on issue and dimension scales as a whole using a different numerator $(L+R+1)$. It is used here to measure the emphasis placed on individual components.
} 


$$
\theta^{I_{2}}=\frac{\log (S+1)}{\log (N+1)}
$$

As in the earlier scale an additional value is added to the number of quasi-sentences in a component in order to prevent calculation problems when the number of quasi-sentences in zero. The value 1 is chosen because $\log (1)=0$, which makes the value of no quasi-sentences in a component consistently 0 . It is added to the total number of quasi-sentences in a manifesto for consistency.

Although unlike the Lowe et al. scale, the scale proposed here a stable zero value, it is perfectly correlated with the values generated by the Lowe et al. scale for any specific manifesto. It also has the additional advantage over the Lowe et al. scale in its ease of interpretability as the new scale is a ratio of log values, rather than a logit, and ranges from 0 to 1 , with a higher number indicating greater emphasis is placed on a component. The Lowe et al. scale by contrast unintuitively ranges from somewhere between -4 and -7 and gets closer to 0 as greater emphasis is placed on a component.

In any manifesto at least some components in the manifesto coding scheme will not be mentioned at all. For all 55 components the range of manifestos mentioning a component ranges from $6.05 \%$ to $89.07 \%$, with a mean of $48.47 \%$ of manifestos mentioning a component. The large number of manifestos not mentioning a component creates potential problems for measuring the relationship between components, a problem known in the literature as the 'structural zero problem'. The easiest solution to this problem is simply to exclude the empty cases from analysis. For methods that rely on analysing multiple components simultaneously, such as factor analysis or multi-dimensional scaling, this is obviously a serious problem. Not even a single manifesto mentions all of the components and so a listwise deletion strategy is obviously impossible, and a pairwise deletion strategy runs the risk of introducing biased estimates into the analysis (Brown, 1983). The method used here sidesteps these problems by analysing each individual component separately. Thus the 
final measure of the relationship between a component and a scale is the exogenous correlation between all non-zero cases of a component and a scale.

The different possible methods of measuring the relationship between a component and a scale are shown in table 3, which demonstrates that these considerations are not just theoretical concerns. The choice of salience measure changes the size and in some cases, the direction, of the exogenous correlation between a scale and its components. A positive correlation indicates the component is correlated with the 'right' side of the scale and a negative correlation indicates a correlation with the 'left'. The results shown in table 3 also indicate that many of the components included in the Rile scale are poorly correlated with the scale: five components have correlations in the opposite direction to what we would expect from their positions in the scale, and several components have correlations close to zero.

[table 3 about here]

\section{Scale building}

The scale building process begins with the construction of a single dimensional 'general left-right' scale, and starts by setting the threshold of exogenous correlation a component must have for it to be included in a scale. This is done by examining the exogenous correlations of all non-zero cases of manifesto components with a scale constructed using the components included in MARPOR's Rile scale (shown in table 1 and table 2). The distribution of the exogenous correlations, shown in figure 2, displays a clear trend, with two peaks of uncorrelated and correlated components. The junction between the two suggests itself as an obviously breakpoint in the data and so the initial threshold for inclusion is set at its value: 0.15 . Thus any component with an exogenous correlation with an absolute value of less than 0.15 will be excluded from a scale.

[figure 2 about here] 
The scale constructed from the Rile components then provides the 'naïve' starting scale for an iterative stepwise process of component selection:

The exogenous correlations between the scale and all non-zero cases of all components are measured.

Any component not already included in the scale with an exogenous correlation greater than 0.15 is added to the scale. Any component currently included in a scale with an exogenous correlation less than 0.15 is removed from the scale.

Steps 1 and 2 are repeated until the scale reaches a stable equilibrium point where all components with an exogenous correlation above the threshold are included in the scale and all components with an exogenous correlation below the threshold are excluded.

Next the distribution of the exogenous correlations with the stable scale are measured to see if the breakpoint between correlated and uncorrelated components has shifted, which it has, to 0.1.

Steps 1-4 are repeated with the new threshold of 0.1 . The second interaction of step 4 does not reveal a change in the threshold and so the stable scale at this point is taken as the final scale.

The scale building process for the new general left-right scale takes 12 iterations (six at each of the threshold values) to reach a stable configuration. The results of the exogenous correlations at each step are shown in table A1 of appendix 1. The components included in the final scale are shown in table 4.

[table 4 about here]

This process is then repeated for the two dimensional scales. First, the 53 manifesto components are divided into 'economic' and 'social' categories, shown in table A2 of the appendix. Where the category of a component is ambiguous it is tested against both economic and social scales, as is the case for seven components. 
The Benoit and Laver (2007), and Bakker and Hobolt (2013) economic and social scales are then used to provide the starting point for initial 'naïve' scales. The exogenous correlations between each scale and its components are shown in table $\mathrm{A} 3$ of the appendix. Like the rile scale the exogenous correlation analysis shows that there are several components in each scale that are poorly correlated with the overall scale, which highlights the necessity of developing new manifesto scales. The component 201 (positive mentions of Freedom and Human Rights) is worth particular attention as its inclusion on opposite sides of the scale in the Benoit and Laver, and Bakker and Hobolt scales (the 'conservative' and 'libertarian' sides respectively) was discussed earlier. For both scales however the component is correlated with the liberal/libertarian side of the scale, suggesting that its inclusion on the 'conservative' side of the Benoit and Laver scale is erroneous. The components for each naïve starting scale are selected by taking all the components included in either economic or social scale that have an exogenous correlation above the 0.1 threshold used for the general leftright scale. The new naïve scales are then measured against the relevant components and a natural break point is found, also at 0.1 . Using this threshold the scale building steps are repeated until the scales have reached a stable equilibrium. In neither case does a re-examination of the distribution of exogenous correlations in step 4 suggest a new threshold and so the components for both scales are chosen in one sequence. The economic left-right scale takes four iterations to reach equilibrium, the results of which are shown in table A4 of the appendix.

In the third iteration of the social liberal-conservative scale a cycling problem occurs. When neither of two components (204 and 602) are included in the scale both are correlated above the threshold value, however when either of them are included in the scale the other does not reach the threshold value. Following the normal procedure results in a cycle between the second and third interaction scales - when they are excluded from the scale the procedure suggest they should be included, when they are included the procedure says they should be excluded. To break this cycle the components are included separately and the component with the highest correlation (602) is 
selected to remain in the scale, which remains stable at this point and so is used as the final scale. The results of the scale building process are shown in table $\mathrm{A} 5$ of the appendix.

One final consideration is necessary before finalising the component selection. Four of the components that were not clearly classifiable as economic or social issues (301: Decentralisation, 416: Anti-growth economics, 705: Underprivileged minority groups, and 706: Non-economic demographic groups) are correlated above the threshold with both the economic and social scales. All four components are correlated with the left side of the economic scale and the liberal side of the social scale, perhaps indicating that these are all what Kitschelt (1988) has called left-libertarian issues. To avoid potential problems of endogenous collinearity between the two dimensions they should be removed from one of the scales. In all cases the components are more highly correlated with the social dimension and so they are removed from the economic scale. Doing so does not cause any significant change to the economic scale, the scale without the components has a correlation of 0.9884 and a Cronbach's alpha of 0.9942 when compared to the scale with the components. The final component selection for each of the two scales is shown in table 5.

[table 5 about here]

\section{Overall content validity and reliability}

Now that the components of the new scales have been selected we can assess the overall content validity of the components included in the scales and compare it to the reference scales. In order to do so the mean direction corrected exogenous correlation - that is correct 'left' components (which have a negative correlation with the overall scale) are given their positive value, incorrect left components are given their negative value, 'right' components are kept the same - of all components in each scale is measured. The results of this calculation are shown in table 6 and demonstrate that each new scale offers an improvement on each of the reference scales. The general left-right scale offers a $62 \%$ improvement in the average correlation of components compared to the Rile scale. The new economic left-right scale presents a $30 \%$ and $51 \%$ improvement 
to the Benoit and Laver and Bakker and Hobolt scales respectively. Finally the new social liberalconservative scale shows $123 \%$ and $56 \%$ improvement over the Benoit and Laver, and Bakker and Hobolt scales respectively.

[table 6 about here]

As well as improving the content validity of the components used to generate scales, the exogenous correlation approach may also improve the general reliability of the scales when compared to the reference scales. Although the validity and reliability of scales are two distinct concepts, improving the validity of the components used to generate a scale may also result in a reduction of nonsystematic error. An 'invalid' scale component is here defined as a scale component that does not relate systematically to the overall scale. If such components are included in a scale they will introduce non-systematic variation in the scale position - that is, error. The overall reliability of the scale is measured using the method developed by McDonald and Budge (forthcoming). The results, also shown in table 6 demonstrate that the new scales are more reliable than all but one of the reference scales. Interestingly the one reference scale that scores a higher reliability coefficient - the Benoit and Laver Social Liberal-Conservative scale - is also the scale that scores lowest on the overall content validity measure (indeed the average exogenous correlation of the scale components is below the threshold values used to construct the new scales). If anything, this combination of results simply illustrates the difference between validity and reliability - a scale can be valid and unreliable, or invalid and reliable, both, or neither - in this case it appears the Benoit and Laver social scale is an invalid and reliable scale, and so not too much weight should be given to the fact that it has a slightly higher reliability coefficient than the new social scale.

Also notable is that in all cases the social scales are have both a lower overall content validity and reliability than their economic scale counterparts. The average content validity of the new scale are still well above the threshold value and the reliability coefficient are above conventional standards of acceptability, and so we should by no means dismiss the social scales. It may suggest however 
that scales based on manifestos are better at measuring economic issues than they are at measuring social issues, which may been an issue for future research to explore.

\section{Dimensionality}

Now that the new scales have been developed it is possible to briefly address the question of whether political space is best represented by one or two dimensions. The correlation between the two dimensional scales is 0.2209 , indicating a small trend from the left/liberal quadrant to the right/conservative quadrant. This trend is ambiguous evidence for answering the question on the number of dimensions: although it does offer some support to a single dimension interpretation of political space, the trend is weak, and an examination of the relationship between the two dimensions in figure 3 shows the relationship is far from linear, and there are many parties in the left/conservative and right/liberal quadrants as well.

[figure 3 about here]

More interesting evidence to answer this question is found by examining the relationship between the two dimensions on a country by country basis, as shown in table A6 in the appendix. Three distinct relationships between the two dimensions emerge: a positive correlation, indicating a trend for left/liberal parties and right/conservative, as found in most Western countries; no significant correlation between the two dimensions, indicating an orthogonal relationship; and a negative correlation, indicating a trend for left/conservative parties and right/liberal parties found in several Eastern European countries. These findings fit well with the existing literature: Kitschelt's (1988) left/libertarian thesis was primarily based on an examination of Western European countries, whilst Marks et al. (2006) have shown that partisan alignment in many Eastern European countries has taken on a left/conservative-right/liberal shape.

The answer to the question of how many dimensions to include in analysis ultimately depends on the context of the research question. For case studies of some (but certainly not all) individual countries a single dimension may be sufficient to capture the ideological differences between 
parties. In many cases however it is clear that a two dimensional interpretation of political space is necessary, and no single dimension can capture the different alignment of the economic and social dimensions between countries and so they must be treated separately.

\section{Conclusion}

Researchers wanting to use dimensional scales based on MARPOR's manifesto dataset are faced with a wide array of different scales, with different conceptions of the underlying dimensionality and assumptions about how individual components relate to the overall scale. A fundamental question when choosing scales is the question of the underlying dimensionality of political space. Until now researchers have been forced to choose between making a priori decisions about the dimensionality or comparing scales constructed using different methods and based on different assumptions. The scales here are constructed for the explicit purpose of providing a set of scales constructed using a uniform methodology that match the most commonly used conceptions of political space: either as a one dimensional 'general left-right' space or a two dimensional 'economic left-right' and 'social liberal-conservative' space.

Too often manifesto scales have been constructed with opaque or inappropriate assumptions about how the underlying components relate to the overall scale. In order to construct the new scales this article embarked on an analysis of previous methods of measuring and combining manifesto components into scales which makes plain the assumptions and reasoning behind the scales constructed here. However the reader should not mistake the critique of previous manifesto scales for a dismissal of their general validity - a reoccurring theme of the analysis, and one of the central premises on which the new scale construction method is based, is that manifesto scales are remarkably robust to potential miscoding.

Given the general robustness of previous scales the reader might be forgiven for wondering what the point of yet another new set of manifesto scales is. This, however, would be to mistake 'fine' for 
'perfect' - which is not of course to say that the scales developed here are perfect. Rather the method here is offered in the spirit of the scientific goal of incremental improvement and modest progress. By offering a set of comparable scales across different conceptions of dimensionality the resulting scales fills an important gap in the body of existing scales based on manifesto data.

The analysis here should also not be mistaken for an attempt to provide the 'final word' on the validity of manifesto scales. There is no one way of assessing the validity of a scale - it must be assessed by a range of different criteria including construct, convergent, content, criterion, discriminant, and predictive validity. Although MARPOR has attempted to validate their Rile scale against many of these measures, the recent literature on scale building has tended to focus largely on convergent validity, specifically cross-validation of scales with expert surveys. Without wishing to deny the importance of convergent validity this article hopes to (re)introduce other criteria to the discussion about the validity of manifesto scales. The focus here has been on only one of these: content validity. A great deal of further work is required to assess the validity of different manifesto scales and scaling methods by other criteria. Such work might go a long way to resolving the ongoing debates about the validity and relative merit of different scales and perhaps help begin to reverse the trend of increasing disagreement over manifesto scales and scaling methods.

\section{Acknowledgements}

This article benefited immensely from comments on earlier versions from Geoff Evans, Catherine de Vries, Steve Fisher, and particularly lan Budge. Any remaining errors and weaknesses are my own. 


\section{References}

Bakker, R., Hobolt, S., 2013. Measuring Party Positions, in: Evans, G., de Graaf, N.D. (Eds.), Political Choice Matters. Oxford University Press, Oxford.

Bakker, R., Jolly, S., Polk, J., 2012. Complexity in the European party space: Exploring dimensionality with experts. European Union Politics 13, 219-245.

Benoit, K., Laver, M., 2007. Estimating party policy positions: Comparing expert surveys and handcoded content analysis. Electoral Studies 26, 90-107.

Benoit, K., Laver, M., 2012. The dimensionality of political space: Epistemological and methodological considerations. European Union Politics 13, 194-218.

Brown, C.H., 1983. Asymptotic comparison of missing data procedures for estimating factor loadings. Psychometrika 48, 269-291.

Budge, I., 1987. The internal analysis of election programmes, in: Budge, I., Robertson, D., Hearl, D.J. (Eds.), Ideology, Strategy and Party Change. Cambridge University Press, Cambridge.

Budge, I., 2000. Expert judgements of party policy positions: uses and limitations in political research. European Journal of Political Research 37, 103-113. doi:10.1111/1475-6765.00506

Budge, I., 2001. Validating party policy placements. British Journal of Political Science 31, 179-223.

Budge, I., Klingemann, H.-D., Volkens, A., Bara, J., Tanenbaum, E., 2001. Mapping policy preferences: estimates for parties, electors, and governments, 1945-1998. Oxford University Press, Oxford and New York.

Elff, M., 2013. A Dynamic State-Space Model of Coded Political Texts. Political Analysis 21, 217-232. Franzmann, S., Kaiser, A., 2006. Locating Political Parties in Policy Space: A reanalysis of Party manifesto data. Party Politics 12, 163-188.

Gabel, M.J., Huber, J.D., 2000. Putting parties in their place: inferring party left-right ideological positions from party manifesto data. American Journal of Political Science 44, 94-103.

Henjak, A., 2010. Political Cleavages and Socio-economic context: how welfare regimes and historical divisions shape political cleavages. West European Politics 33, 474-504. 
Hooghe, L., Bakker, R., Brigevich, A., de Vries, C.E., Edwards, E., Marks, G., Rovny, J., Steenbergen, M.R., Vachudova, M., 2010. Reliability and Validity of Measuring Party Positions: The Chapel Hill Expert Surveys of 2002 and 2006. European Journal of Political Research 49, 687-703.

Jahn, D., 2011. Conceptualizing Left and Right in comparative politics: Towards a deductive approach. Party Politics 17, 745-765.

Kim, H., Fording, R.C., 1998. Voter Ideology in Western Democracies, 1946-1989. European Journal of Political Research 33, 73-97.

Kitschelt, H., 1988. Left-libertarian parties: Explaining innovation in competitive party systems. World Politics 40, 194-234.

Klingemann, H.-D., 1995. Party positions and voter orientations, in: Klingemann, H.-D., Fuch, D. (Eds.), Citizens and the State. Oxford University Press, Oxford.

Klingemann, H.-D., Volkens, A., Bara, J., Budge, I., McDonald, M.D., 2006. Mapping policy preferences II: estimates for parties, electors, and governments in Central and Eastern Europe, European Union and OECD 1990-2003. Oxford University Press, Oxford and New York.

König, T., Luig, B., 2012. Party ideology and legislative agendas: Estimating contextual policy positions for the study of EU decision-making. European Union Politics 13, 604-625.

König, T., Marbach, M., Osnabrügge, M., 2013. Estimating Party Positions across Countries and Time-A Dynamic Latent Variable Model for Manifesto Data. Political Analysis 21, 468-491. doi:10.1093/pan/mpt003

Laver, M., Budge, I., 1992. Measuring policy distances and modelling coaltion formation, in: Party Policy and Government Coalitions. MacMillan, Houndmills, Basingstoke, Hampshire.

Laver, M., Hunt, B.W., 1992. Policy and party competition. Routledge, New York. Lawshe, C.H., 1975. A quantitative approach to content validity. Personnel Psychology 28, 563-575. Lowe, W., Benoit, K., Mikhaylov, S., Laver, M., 2011. Scaling Policy Preferences from Coded Political Texts. Legislative Studies Quarterly 36, 123-155. 
Marks, G., Hooghe, L., Nelson, M., Edwards, E., 2006. Party competition and European integration in the East and West: Different structure, same causality. Comparative Political Studies 39, 155-175.

McDonald, M.D., Budge, I., forthcoming. Getting it (approximately) right (and centre and left). Electoral Studies.

Ray, L., 2007. Validity of measured party positions on European integration: Assumptions, approaches, and a comparison of alternative measures. Electoral Studies 26, 11-22.

Ridout, M., Demétrio, C.G.B., Hinde, J., 1998. Models for count data with many zeros. Presented at the International Biometric Conference, Cape Town.

Schofield, N., 1993. Political competition and multiparty coalition governments. European Journal of Political Research 23, 1-33.

Steenbergen, M.R., Marks, G., 2007. Evaluating expert judgments. European Journal of Political Research 46, 347-366. doi:10.1111/j.1475-6765.2006.00694.x

Stoll, H., 2010a. Dimensionality and the number of parties in legislative elections. Party Politics 17, 405-429.

Stoll, H., 2010b. Elite-Level Conflict Salience and Dimensionality in Western Europe: Concepts and Empirical Findings. West European Politics 33, 445-473.

Van der Broug, W., 2001. Analysing party dynamics by taking partially overlapping snapshots, in: Laver, M. (Ed.), Estimating the Policy Positions of Political Actors. Routledge, London, pp. 115-132. Volkens, A., 2007. Strengths and weaknesses of approaches to measuring policy positions of parties. Electoral Studies 26, 108-120. doi:10.1016/j.electstud.2006.04.003

Volkens, A., Lacewell, O., Regel, S., Schultze, H., Werner, A., 2009. The Manifesto Data Collection. Manifesto Project (MRG/CMP/MARPOR). Wissenschaftszentrum Berlin für Sozialforschung (WZB), Berlin.

Warwick, P., 2002. Towards a common dimensionality in west European policy spaces. Party Politics $8,101-122$. 
Wedel, M., Bökenhold, U., Kamakura, W.A., 2003. Factor models for multivariate count data. Journal of Multivariate Analysis 87, 356-369. 


\section{Figures}
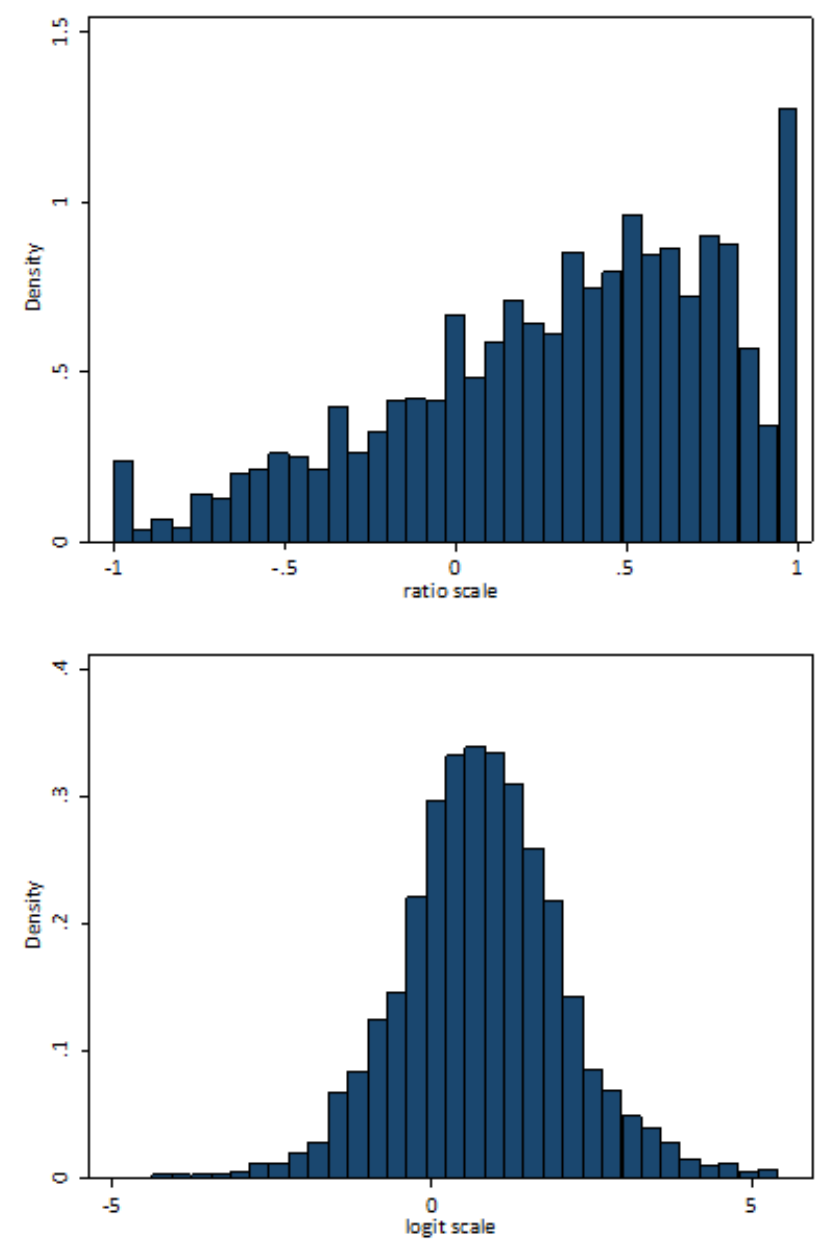

FIGURE 1. COMPARISON OF THE DISTRIBUTION OF A POLICY SCALE CONSTRUCTED USING THE BENOIT AND LAVER SOCIAL LIBERAL-CONSERVATIVE SCALE COMPONENTS USING THE KIM-FORDING RATIO METHOD AND THE LOWE ET AL. (2011) LOGIT METHOD. 


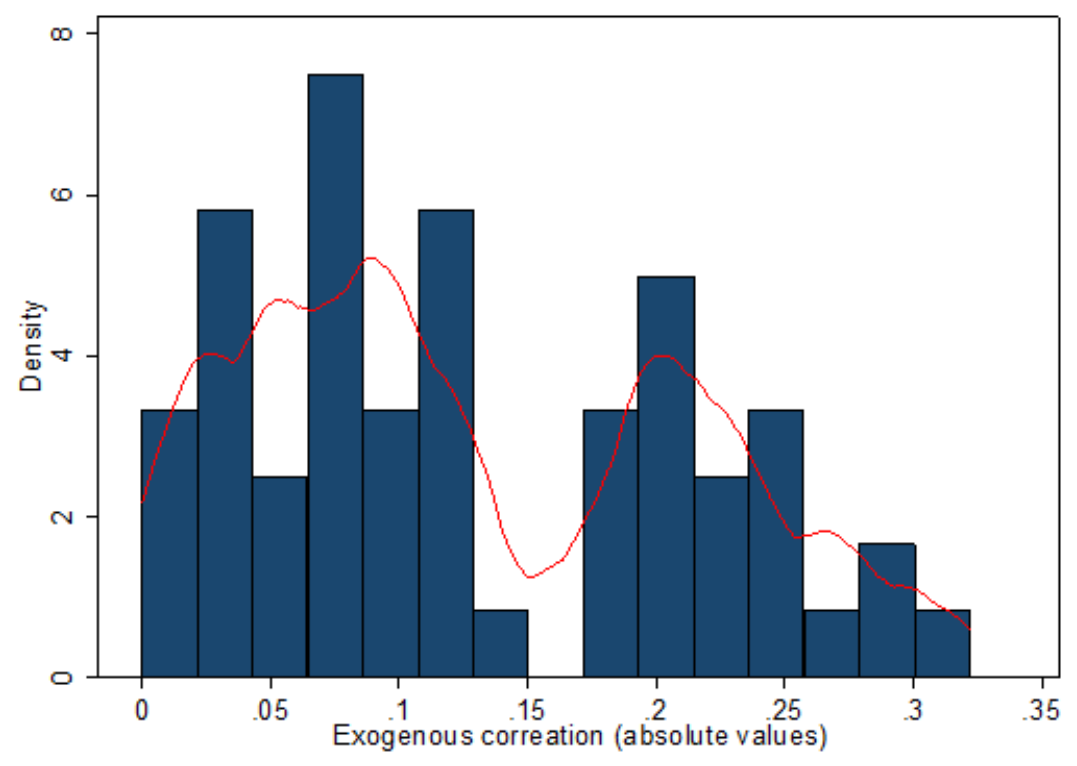

FIGURE 2. EXOGENOUS CORRELATIONS (ABSOLUTE VALUES) OF SCALE COMPONENTS WITH A SCALE CONSTRUCTED USING MARPOR'S RILE COMPONENTS AND LOWE ET AL.'S (2011) LOGIT METHOD.

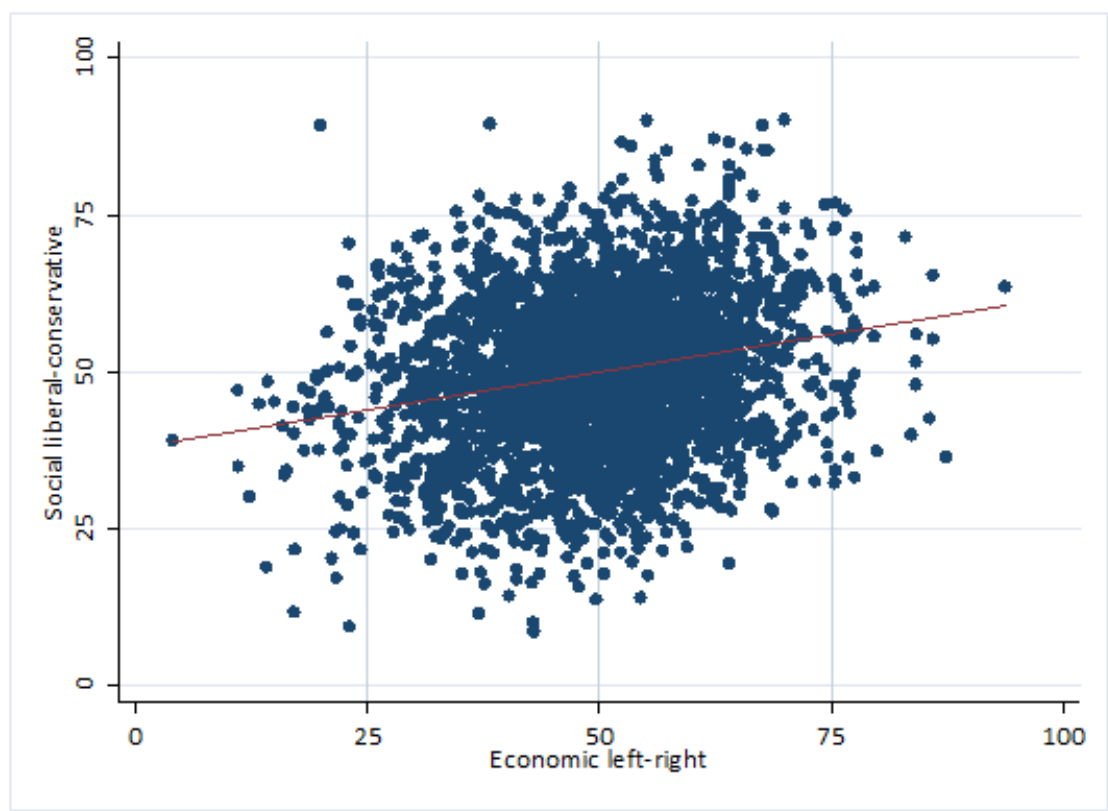

FIGURE 3. RELATIONSHIP BETWEEN THE ECONOMIC LEFT-RIGHT AND SOCIAL LIBERALCONSERVATIVE SCALES FOR ALL OBSERVATIONS IN THE MARPOR DATASET. 
Tables

\begin{tabular}{|c|c|c|c|}
\hline \multicolumn{2}{|r|}{ Left } & \multicolumn{2}{|r|}{ Right } \\
\hline \multicolumn{4}{|c|}{ MARPOR 'Rile' } \\
\hline 103 & Anti-imperialism: Anti-Colonialism & 104 & Military: Positive \\
\hline 105 & Military: Negative & 201 & Freedom and Human Rights: Positive \\
\hline 106 & Peace: Positive & 203 & Constitutionalism: Positive \\
\hline 107 & Internationalism: Positive & 305 & Political Authority: Positive \\
\hline 202 & Democracy: Positive & 401 & Free Enterprise: Positive \\
\hline 403 & Market Regulation: Positive & 402 & Incentives: Positive \\
\hline 404 & Economic Planning: Positive & 407 & Protectionism: Negative \\
\hline 406 & Protectionism: Positive & 414 & Economic Orthodoxy: Positive \\
\hline 412 & Controlled Economy: Positive & 505 & Welfare State Limitation: Positive \\
\hline 413 & Nationalisation: Positive & 601 & National Way of Life: Positive \\
\hline 504 & Welfare State Expansion: Positive & 603 & Traditional Morality: Positive \\
\hline 506 & Education Expansion: Positive & 605 & Law and Order: Positive \\
\hline 701 & Labour Groups: Positive & 606 & Social Harmony: Positive \\
\hline \multicolumn{4}{|c|}{ Benoit and Laver (2007) State involvement in economy } \\
\hline 403 & Market Regulation: Positive & 401 & Free Enterprise: Positive \\
\hline 404 & Economic Planning: Positive & 402 & Incentives: Positive \\
\hline 406 & Protectionism: Positive & 407 & Protectionism: Negative \\
\hline 412 & Controlled Economy: Positive & 414 & Economic Orthodoxy: Positive \\
\hline 413 & Nationalisation: Positive & 505 & Welfare State Limitation: Positive \\
\hline 504 & Welfare State Expansion: Positive & & \\
\hline 506 & Education Expansion: Positive & & \\
\hline 701 & Labour Groups: Positive & & \\
\hline \multicolumn{4}{|c|}{ Bakker-Hobolt (2013) left-right } \\
\hline 403 & Market Regulation: Positive & 401 & Free Enterprise: Positive \\
\hline 404 & Economic Planning: Positive & 402 & Incentives: Positive \\
\hline 405 & Corporatism & 407 & Protectionism: Negative \\
\hline 406 & Protectionism: Positive & 410 & Productivity: Positive \\
\hline 412 & Controlled Economy: Positive & 414 & Economic Orthodoxy: Positive \\
\hline 413 & Nationalisation: Positive & 505 & Welfare State Limitation: Positive \\
\hline 409 & Keynesian Demand Management & 507 & Education Limitation: Positive \\
\hline 415 & Marxist Analysis: Positive & 702 & Labour Groups: Negative \\
\hline 503 & Social Justice & & \\
\hline 504 & Welfare State Expansion: Positive & & \\
\hline 506 & Education Expansion: Positive & & \\
\hline 701 & Labour Groups: Positive & & \\
\hline
\end{tabular}




\begin{tabular}{|c|c|c|c|}
\hline \multicolumn{4}{|c|}{ Benoit and Laver (2007) Social liberal-conservative } \\
\hline \multicolumn{3}{|c|}{ Liberal } & Conservative \\
\hline 103 & Anti-imperialism: Anti-Colonialism & 104 & Military: Positive \\
\hline 105 & Military: Negative & 201 & Freedom and Human Rights: Positive \\
\hline 106 & Peace: Positive & 203 & Constitutionalism: Positive \\
\hline 107 & Internationalism: Positive & 305 & Political Authority: Positive \\
\hline \multirow[t]{4}{*}{202} & Democracy: Positive & 601 & National Way of Life: Positive \\
\hline & & 603 & Traditional Morality: Positive \\
\hline & & 605 & Law and Order: Positive \\
\hline & & 606 & Social Harmony: Positive \\
\hline \multicolumn{4}{|c|}{ Bakker-Hobolt (2013 Libertarian-authoritarian } \\
\hline & Libertarian & & Authoritarian \\
\hline 201 & Freedom and Human Rights: Positive & 305 & Political Authority: Positive \\
\hline 202 & Democracy: Positive & 601 & National Way of Life: Positive \\
\hline 416 & Anti-Growth Economy & 603 & Traditional Morality: Positive \\
\hline 501 & Environmental Protection & 605 & Law and Order: Positive \\
\hline 502 & Culture & 606 & Social Harmony: Positive \\
\hline 602 & National Way of Life: Negative & 608 & Multiculturalism: Negative \\
\hline 604 & Traditional Morality: Negative & & \\
\hline 607 & Multiculturalism: Negative & & \\
\hline 705 & Underprivileged Minority Groups & & \\
\hline 706 & Non-economic Demographic Groups & & \\
\hline
\end{tabular}




\begin{tabular}{|c|c|c|c|c|c|}
\hline & Component & $\begin{array}{l}\text { Percentage } \\
\text { salience }\end{array}$ & $\begin{array}{c}\text { Lowe et al. } \\
\text { salience }\end{array}$ & $\begin{array}{c}\text { Ratio of logs } \\
\text { salience }\end{array}$ & $\begin{array}{l}\text { Ratio of logs } \\
\text { salience if }>0\end{array}$ \\
\hline \multirow{13}{*}{ ‘Right' } & 104 & 0.1051 & 0.089 & 0.0746 & 0.0482 \\
\hline & 201 & 0.015 & -0.0652 & -0.0761 & -0.0718 \\
\hline & 203 & 0.0279 & -0.0005 & -0.0174 & 0.0447 \\
\hline & 305 & 0.0646 & 0.0397 & 0.0427 & 0.0726 \\
\hline & 401 & 0.28 & 0.2638 & 0.2711 & 0.2482 \\
\hline & 402 & 0.0466 & -0.0224 & -0.0273 & -0.0294 \\
\hline & 407 & 0.0595 & 0.0612 & 0.0188 & 0.1109 \\
\hline & 414 & 0.2026 & 0.1224 & 0.1505 & 0.2142 \\
\hline & 505 & 0.202 & 0.234 & 0.1927 & 0.2734 \\
\hline & 601 & 0.1943 & 0.1824 & 0.1929 & 0.1899 \\
\hline & 603 & 0.1132 & 0.1862 & 0.1704 & 0.1063 \\
\hline & 605 & 0.089 & -0.0006 & -0.0057 & -0.0252 \\
\hline & 606 & 0.0411 & 0.0139 & 0.0001 & -0.0034 \\
\hline \multirow{13}{*}{ 'Left' } & 103 & -0.0728 & -0.095 & -0.1441 & -0.0316 \\
\hline & 105 & -0.2402 & -0.2986 & -0.3579 & -0.296 \\
\hline & 106 & -0.1047 & -0.2468 & -0.2811 & -0.2058 \\
\hline & 107 & -0.1441 & -0.1748 & -0.2041 & -0.1849 \\
\hline & 202 & 0.0103 & -0.1367 & -0.1244 & -0.0782 \\
\hline & 403 & -0.1665 & -0.214 & -0.225 & -0.1484 \\
\hline & 404 & -0.1194 & -0.1874 & -0.2156 & -0.1138 \\
\hline & 406 & 0.0044 & -0.0017 & -0.0435 & 0.0319 \\
\hline & 412 & -0.1737 & -0.2056 & -0.252 & -0.2009 \\
\hline & 413 & -0.2689 & -0.2684 & -0.3406 & -0.2889 \\
\hline & 504 & -0.1621 & -0.2053 & -0.2192 & -0.1951 \\
\hline & 506 & -0.0909 & -0.1376 & -0.1447 & -0.1286 \\
\hline & 701 & -0.2442 & -0.2751 & -0.3107 & -0.2571 \\
\hline
\end{tabular}

TABLE 3. COMPAISION OF EXOGENOUS SALIENCE BETWEEN COMPONENTS IN A LOGIT 'RILE' SCALE USING DIFFERENT SALIENCE MEASURES. 


\begin{tabular}{|c|c|c|c|}
\hline \multicolumn{4}{|c|}{ General left-right scale } \\
\hline \multicolumn{2}{|r|}{ Left } & \multicolumn{2}{|r|}{ Right } \\
\hline 105 & Military: Negative & 109 & Internationalism: Negative \\
\hline 106 & Peace & 401 & Free Enterprise: Positive \\
\hline 107 & Internationalism: Positive & 407 & Protectionism: Negative \\
\hline 108 & European Integration: Positive & 414 & Economic Orthodoxy: Positive \\
\hline 202 & Democracy & 505 & Welfare State Limitation: Positive \\
\hline 301 & Decentralisation & 507 & Education Limitation: Positive \\
\hline 303 & Governmental and Administrative Efficiency & 601 & National Way of Life: Positive \\
\hline 403 & Market Regulation: Positive & 603 & Traditional Morality: Positive \\
\hline 408 & Economic Goals & 608 & Multiculturalism: Negative \\
\hline 411 & Technology and Infrastructure & 702 & Labour Groups: Negative \\
\hline 412 & Controlled Economy: Positive & & \\
\hline 413 & Nationalisation: Positive & & \\
\hline 416 & Anti-Growth Economy & & \\
\hline 501 & Environmental Protection & & \\
\hline 502 & Culture & & \\
\hline 503 & Social Justice & & \\
\hline 504 & Welfare State Expansion: Positive & & \\
\hline 506 & Education Expansion: Positive & & \\
\hline 602 & National Way of Life: Negative & & \\
\hline 604 & Traditional Morality: Negative & & \\
\hline 701 & Labour Groups: Positive & & \\
\hline 705 & Underprivileged Minority Groups & & \\
\hline 706 & Non-economic Demographic Groups & & \\
\hline
\end{tabular}




\begin{tabular}{llll}
\hline \multicolumn{1}{c}{ Left } & \multicolumn{1}{c}{ Economic left right } \\
\hline 403 & Market Regulation: Positive & 401 & Free Enterprise: Positive \\
411 & Technology and Infrastructure & 407 & Protectionism: Negative \\
412 & Controlled Economy: Positive & 414 & Economic Orthodoxy: Positive \\
413 & Nationalisation: Positive & 505 & Welfare State Limitation: Positive \\
503 & Social Justice & 507 & Education Limitation: Positive \\
504 & Welfare State Expansion: Positive & 702 & Labour Groups: Negative \\
506 & Education Expansion: Positive & & \\
701 & Labour Groups: Positive & & \\
\hline
\end{tabular}

Social Liberal Conservative

Liberal

Conservative

\begin{tabular}{llll}
\hline 105 & Military: Negative & 109 & Internationalism: Negative \\
106 & Peace & 302 & Centralisation \\
107 & Internationalism: Positive & 305 & Political Authority: Positive \\
201 & Freedom and Human Rights & 601 & National Way of Life: Positive \\
202 & Democracy & 608 & Multiculturalism: Negative \\
301 & Decentralisation & & \\
416 & Anti-Growth Economy & & \\
501 & Environmental Protection & \\
502 & Culture & \\
602 & National Way of Life: Negative & \\
607 & Multiculturalism: Positive & \\
704 & Middle Class and Professional Groups & \\
705 & Underprivileged Minority Groups & \\
706 & Non-economic Demographic Groups & \\
\hline \multicolumn{2}{c}{ TABLE 5. FINAL COMPONENT SELECTION FOR THE TWO DIMENSIONAL ECONOMIC AND SOCIAL SCALES. }
\end{tabular}




\begin{tabular}{cccc}
\hline Dimensions & Scale components & $\begin{array}{c}\text { Overall internal validity } \\
\text { (Mean exogenous } \\
\text { correlation of } \\
\text { components with scale) }\end{array}$ & $\begin{array}{c}\text { Overall reliability } \\
\text { (McDonald and Budge } \\
\text { Reliability coefficient) }\end{array}$ \\
\cline { 2 - 4 } One & MARPOR Rile & 0.1260 & 0.8587 \\
& New general left-right & 0.2041 & 0.8964 \\
\hline \multirow{2}{*}{ Two } & B State involvement in economy & 0.1675 & 0.8494 \\
& BH left-right & 0.1448 & 0.8573 \\
& BL social liberal-conservative & 0.2185 & 0.8679 \\
& BH libertarian-authoritarian & 0.0799 & 0.8061 \\
& New social liberal-conservative & 0.1146 & 0.7682 \\
\end{tabular}


Appendix to:

\section{Building policy scales from manifesto data: a referential content}

$$
\text { validity approach }
$$

\section{Contents}

TABLE 1. RESULTS OF EACH STAGE OF THE COMPONENT SELECTION PROCESS FOR THE ONE DIMENSIONAL GENERAL LEFT-RIGHT SCALE. CORRELATIONS IN BOLD INDICATE COMPONENTS THAT WERE INCLUDED IN THE SCALE IN THAT ITERATION.

TABLE 2. ECONOMIC, SOCIAL, AND AMBIGUOUS MANIFESTO COMPONENTS.

TABLE 3. EXOGENOUS CORRELATIONS BETWEEN FOUR EXISTINGS MANIFESTO SCALES AND THEIR COMPONENTS.

TABLE 4. RESULTS OF EACH STAGE OF THE COMPONENT SELECTION PROCESS FOR THE ECONOMIC LEFT-RIGHT SCALE. CORRELATIONS IN BOLD INDICATE COMPONENTS THAT WERE INCLUDED IN THE SCALE IN THAT ITERATION.

TABLE 5. RESULTS OF EACH STAGE OF THE COMPONENT SELECTION PROCESS FOR THE SOCIAL LIBERAL-CONSERVATIVE SCALE. CORRELATIONS IN BOLD INDICATE COMPONENTS THAT WERE INCLUDED IN THE SCALE IN THAT ITERATION.

TABLE 6. CORRELATION BETWEEN THE ECONOMIC AND SOCIAL SCALES FOR ALL COUNTRIES IN THE MARPOR DATASET. 


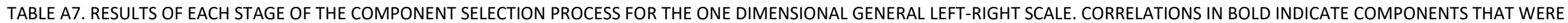
INCLUDED IN THE SCALE IN THAT ITERATION.

\begin{tabular}{|c|c|c|c|c|c|c|c|c|c|c|c|c|}
\hline \multirow[b]{2}{*}{ Component } & \multicolumn{12}{|c|}{ Iteration } \\
\hline & 1 & 2 & 3 & 4 & 5 & 6 & 7 & 8 & 9 & 10 & 11 & 12 \\
\hline 101 & -0.0192 & -0.0487 & -0.0395 & -0.0367 & -0.0385 & -0.0306 & -0.044 & -0.0429 & -0.0447 & -0.0476 & -0.0454 & -0.0464 \\
\hline 102 & -0.1281 & -0.071 & -0.1069 & -0.1133 & -0.114 & -0.1143 & -0.1288 & -0.074 & -0.0903 & -0.0881 & -0.0766 & -0.0751 \\
\hline 103 & -0.0316 & -0.0681 & -0.1373 & -0.1453 & -0.155 & -0.1512 & -0.136 & -0.0748 & -0.0514 & -0.0708 & -0.0288 & -0.0253 \\
\hline 104 & 0.0482 & 0.0958 & 0.0667 & 0.0736 & 0.0818 & 0.0834 & 0.0731 & 0.0952 & 0.0541 & 0.0847 & 0.082 & 0.0786 \\
\hline 105 & -0.296 & -0.3401 & -0.2934 & -0.3023 & -0.3073 & -0.306 & -0.3262 & -0.3313 & -0.2888 & -0.3382 & -0.3162 & -0.3083 \\
\hline 106 & -0.2058 & -0.205 & -0.189 & -0.2022 & -0.206 & -0.2024 & -0.2051 & -0.1877 & -0.1773 & -0.1795 & -0.1717 & -0.1679 \\
\hline 107 & -0.1849 & -0.2467 & -0.1923 & -0.1856 & -0.1822 & -0.1691 & -0.1767 & -0.2354 & -0.197 & -0.2286 & -0.2282 & -0.2311 \\
\hline 108 & -0.0846 & -0.1031 & -0.0729 & -0.0611 & -0.0535 & -0.0625 & -0.0963 & -0.1181 & -0.1166 & -0.1345 & -0.1397 & -0.1555 \\
\hline 109 & 0.079 & 0.1429 & 0.0374 & 0.0313 & 0.0319 & 0.0178 & 0.0273 & 0.134 & 0.0427 & 0.1282 & 0.1284 & 0.1306 \\
\hline 110 & -0.0617 & -0.0383 & -0.0786 & -0.0803 & -0.0809 & -0.0831 & -0.1112 & -0.0465 & -0.0633 & -0.0602 & -0.0418 & -0.042 \\
\hline 201 & -0.0718 & -0.0354 & -0.0369 & -0.0372 & -0.0397 & -0.047 & -0.0542 & -0.0625 & -0.0511 & -0.0658 & -0.0529 & -0.0536 \\
\hline 202 & -0.0782 & -0.1821 & -0.1884 & -0.1833 & -0.1849 & -0.1916 & -0.2107 & -0.1968 & -0.2034 & -0.2042 & -0.1973 & -0.2015 \\
\hline 203 & 0.0447 & 0.0699 & 0.0754 & 0.0814 & 0.0838 & 0.0831 & 0.0432 & 0.0495 & 0.0488 & 0.0183 & 0.0311 & 0.0281 \\
\hline 204 & 0.1043 & 0.0579 & 0.0167 & 0.0254 & 0.0368 & 0.056 & 0.039 & 0.0481 & 0.0366 & 0.0351 & 0.0361 & 0.0365 \\
\hline 301 & -0.1092 & -0.1653 & -0.1487 & -0.1424 & -0.1355 & -0.1293 & -0.1299 & -0.1752 & -0.1763 & -0.1723 & -0.1802 & -0.1881 \\
\hline 302 & 0.0405 & 0.0677 & 0.0713 & 0.0756 & 0.0682 & 0.0745 & 0.0556 & 0.0742 & 0.0541 & 0.0547 & 0.0487 & 0.05 \\
\hline 303 & -0.0001 & -0.0536 & -0.045 & -0.0231 & -0.0099 & -0.0106 & -0.0423 & -0.0792 & -0.0846 & -0.0959 & -0.1086 & -0.1086 \\
\hline 304 & -0.0285 & 0.0086 & 0.0068 & -0.0035 & -0.0055 & -0.007 & -0.0276 & 0.0122 & -0.0175 & -0.0076 & -0.0126 & -0.029 \\
\hline 305 & 0.0726 & 0.105 & 0.0609 & 0.0642 & 0.0637 & 0.0554 & 0.0431 & 0.0726 & 0.0798 & 0.0597 & 0.0799 & 0.0724 \\
\hline 401 & 0.2482 & 0.2265 & 0.2821 & 0.2921 & 0.2966 & 0.3101 & 0.2956 & 0.231 & 0.2602 & 0.227 & 0.2175 & 0.2064 \\
\hline 402 & -0.0294 & 0.0158 & 0.049 & 0.0666 & 0.0772 & 0.0783 & 0.0368 & 0.004 & 0.004 & -0.0182 & -0.0274 & -0.0391 \\
\hline 403 & -0.1484 & -0.1853 & -0.1538 & -0.1399 & -0.1421 & -0.1307 & -0.1456 & -0.1825 & -0.1687 & -0.1939 & -0.1932 & -0.2024 \\
\hline 404 & -0.1138 & -0.0711 & -0.0473 & -0.0386 & -0.0376 & -0.0344 & -0.0556 & -0.0799 & -0.075 & -0.0842 & -0.0946 & -0.0969 \\
\hline 405 & 0.0007 & 0.017 & 0.0399 & 0.045 & 0.0434 & 0.0441 & 0.0291 & 0.0157 & 0.0222 & 0.0053 & -0.0026 & -0.0097 \\
\hline
\end{tabular}




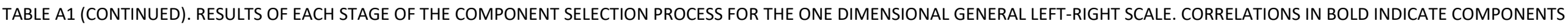
THAT WERE INCLUDED IN THE SCALE IN THAT ITERATION.

\begin{tabular}{|c|c|c|c|c|c|c|c|c|c|c|c|c|}
\hline \multirow[b]{2}{*}{ Component } & \multicolumn{12}{|c|}{ 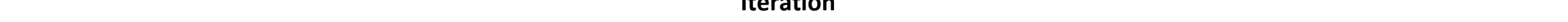 } \\
\hline & 1 & 2 & 3 & 4 & 5 & 6 & 7 & 8 & 9 & 10 & 11 & 12 \\
\hline 406 & 0.0319 & 0.0379 & -0.0341 & -0.0285 & -0.0306 & -0.0239 & -0.0049 & 0.0401 & 0.009 & 0.0394 & 0.0408 & 0.0446 \\
\hline 407 & 0.1109 & 0.1363 & 0.1433 & 0.1498 & 0.1559 & 0.1556 & 0.1238 & 0.1395 & 0.1189 & 0.1173 & 0.1162 & 0.1166 \\
\hline 408 & -0.0655 & -0.0715 & -0.0551 & -0.0422 & -0.041 & -0.0431 & -0.0667 & -0.0769 & -0.0871 & -0.1007 & -0.1061 & -0.1166 \\
\hline 409 & 0.0242 & 0.0425 & 0.048 & 0.047 & 0.0476 & 0.0454 & 0.0321 & 0.0512 & 0.0479 & 0.0334 & 0.032 & 0.0299 \\
\hline 410 & -0.0768 & -0.045 & -0.067 & -0.0389 & -0.0295 & -0.0177 & -0.0544 & -0.0589 & -0.0891 & -0.0788 & -0.088 & -0.0954 \\
\hline 411 & -0.1148 & -0.1619 & -0.121 & -0.1164 & -0.1014 & -0.0921 & -0.1183 & -0.1541 & -0.1425 & -0.1646 & -0.1711 & -0.186 \\
\hline 412 & -0.2009 & -0.2227 & -0.2121 & -0.2143 & -0.2164 & -0.2135 & -0.2096 & -0.2115 & -0.219 & -0.2124 & -0.2123 & -0.2157 \\
\hline 413 & -0.2889 & -0.2306 & -0.2401 & -0.2466 & -0.2423 & -0.2475 & -0.2652 & -0.2301 & -0.2217 & -0.2375 & -0.2107 & -0.2096 \\
\hline 414 & 0.2142 & 0.2114 & 0.2221 & 0.2332 & 0.2387 & 0.2342 & 0.2039 & 0.1999 & 0.1806 & 0.1787 & 0.1659 & 0.1537 \\
\hline 415 & -0.1167 & -0.0345 & -0.0393 & -0.0662 & -0.0866 & -0.112 & -0.0663 & -0.0418 & 0.0087 & -0.0315 & 0.0211 & 0.0232 \\
\hline 416 & -0.2556 & -0.2605 & -0.1989 & -0.2005 & -0.2017 & -0.2006 & -0.2122 & -0.2559 & -0.2373 & -0.2627 & -0.2755 & -0.2822 \\
\hline 501 & -0.2188 & -0.2805 & -0.2357 & -0.2273 & -0.2204 & -0.2132 & -0.2201 & -0.2811 & -0.249 & -0.2728 & -0.272 & -0.2758 \\
\hline 502 & -0.1762 & -0.1774 & -0.1907 & -0.1668 & -0.1515 & -0.1521 & -0.1676 & -0.2032 & -0.2079 & -0.2073 & -0.2162 & -0.2276 \\
\hline 503 & -0.322 & -0.3559 & -0.3386 & -0.3428 & -0.3366 & -0.3322 & -0.3355 & -0.3534 & -0.341 & -0.352 & -0.3461 & -0.3458 \\
\hline 504 & -0.1951 & -0.2591 & -0.2633 & -0.2453 & -0.2192 & -0.2132 & -0.2319 & -0.278 & -0.2764 & -0.2743 & -0.2874 & -0.2917 \\
\hline 505 & 0.2734 & 0.1937 & 0.2301 & 0.2354 & 0.24 & 0.2362 & 0.2077 & 0.1976 & 0.1979 & 0.1738 & 0.1723 & 0.1555 \\
\hline 506 & -0.1286 & -0.1982 & -0.1682 & -0.147 & -0.1473 & -0.1414 & -0.1598 & -0.1928 & -0.2074 & -0.2075 & -0.2213 & -0.2306 \\
\hline 507 & 0.2206 & 0.2689 & 0.2745 & 0.2635 & 0.2578 & 0.2504 & 0.217 & 0.2872 & 0.2376 & 0.2511 & 0.2502 & 0.2458 \\
\hline 601 & 0.1899 & 0.1037 & 0.0986 & 0.0933 & 0.0928 & 0.0858 & 0.1458 & 0.0843 & 0.1732 & 0.1555 & 0.1743 & 0.1765 \\
\hline 602 & -0.0689 & -0.1104 & -0.1542 & -0.1065 & -0.1155 & -0.077 & -0.1414 & -0.1369 & -0.1489 & -0.153 & -0.136 & -0.1328 \\
\hline 603 & 0.1063 & 0.1243 & 0.1059 & 0.103 & 0.1078 & 0.1019 & 0.0988 & 0.1314 & 0.101 & 0.1323 & 0.1317 & 0.1318 \\
\hline 604 & -0.1756 & -0.1914 & -0.1697 & -0.1702 & -0.1655 & -0.1604 & -0.1842 & -0.1868 & -0.2004 & -0.1936 & -0.2031 & -0.2048 \\
\hline 605 & -0.0252 & 0.0085 & 0.0206 & 0.0326 & 0.0446 & 0.0481 & 0.0303 & 0.0018 & -0.0075 & -0.0053 & -0.0155 & -0.0319 \\
\hline 606 & -0.0034 & -0.004 & -0.0107 & -0.016 & -0.0171 & -0.0216 & 0.0022 & -0.007 & 0.0075 & 0.0044 & 0.0083 & 0.0053 \\
\hline
\end{tabular}




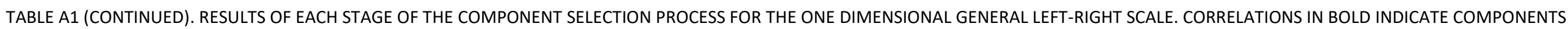
THAT WERE INCLUDED IN THE SCALE IN THAT ITERATION.

\begin{tabular}{|c|c|c|c|c|c|c|c|c|c|c|c|c|}
\hline \multirow[b]{2}{*}{ Component } & \multicolumn{12}{|c|}{ Iteration } \\
\hline & 1 & 2 & 3 & 4 & 5 & 6 & 7 & 8 & 9 & 10 & 11 & 12 \\
\hline 607 & -0.0903 & -0.0932 & -0.0889 & -0.0779 & -0.078 & -0.0721 & -0.0598 & -0.1126 & -0.0706 & -0.0823 & -0.0863 & -0.081 \\
\hline 608 & 0.2174 & 0.1841 & 0.1826 & 0.1822 & 0.1806 & 0.1796 & 0.178 & 0.1868 & 0.1753 & 0.1878 & 0.18 & 0.1769 \\
\hline 701 & -0.2571 & -0.2662 & -0.2685 & -0.2687 & -0.2636 & -0.2613 & -0.2895 & -0.2706 & -0.2517 & -0.2924 & -0.2664 & -0.2673 \\
\hline 702 & 0.2389 & 0.2236 & 0.2181 & 0.2152 & 0.2078 & 0.2202 & 0.1518 & 0.2288 & 0.149 & 0.159 & 0.1532 & 0.1487 \\
\hline 703 & -0.0706 & -0.0192 & -0.0437 & -0.0231 & -0.014 & -0.0075 & -0.0278 & -0.0361 & -0.0559 & -0.0519 & -0.0572 & -0.06 \\
\hline 704 & -0.0956 & -0.0565 & -0.0436 & -0.0399 & -0.0345 & -0.0336 & -0.0058 & -0.0564 & -0.0162 & -0.0288 & -0.0317 & -0.0317 \\
\hline 705 & -0.2118 & -0.2771 & -0.2267 & -0.2168 & -0.2131 & -0.2121 & -0.2253 & -0.2795 & -0.2608 & -0.2779 & -0.2881 & -0.2958 \\
\hline 706 & -0.2094 & -0.2418 & -0.2078 & -0.1921 & -0.1881 & -0.187 & -0.1848 & -0.2511 & -0.2137 & -0.2353 & -0.2456 & -0.2473 \\
\hline
\end{tabular}


TABLE A8. ECONOMIC, SOCIAL, AND AMBIGUOUS MANIFESTO COMPONENTS.

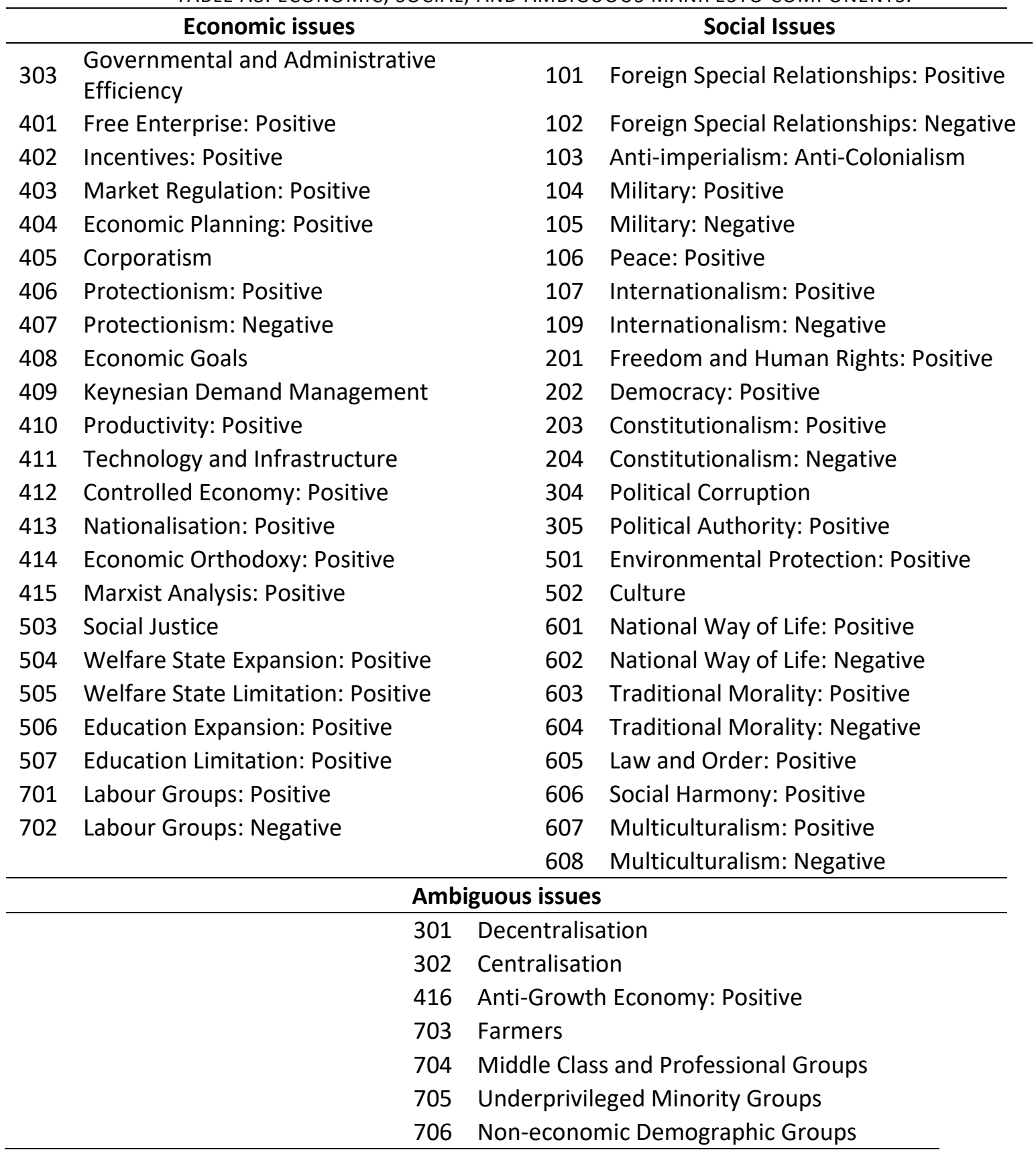


TABLE A9. EXOGENOUS CORRELATIONS BETWEEN FOUR EXISTINGS MANIFESTO SCALES AND THEIR COMPONENTS.

\begin{tabular}{ccc|ccc}
\hline Component & $\begin{array}{c}\text { Benoit-Laver } \\
\text { State } \\
\text { involvement in } \\
\text { economy }\end{array}$ & $\begin{array}{c}\text { Bakker-Hobolt } \\
\text { left-right }\end{array}$ & Component & $\begin{array}{c}\text { Benoit-Laver } \\
\text { Social liberal- } \\
\text { conservative }\end{array}$ & $\begin{array}{c}\text { Bakker-Hobolt } \\
\text { libertarian- } \\
\text { authoritarian }\end{array}$ \\
\hline 401 & 0.3191 & 0.2969 & 103 & -0.0573 & \\
402 & 0.0235 & 0.0522 & 104 & 0.061 & \\
403 & -0.0861 & -0.0966 & 105 & -0.3084 & \\
404 & -0.0633 & -0.0095 & 106 & -0.2496 & \\
405 & & 0.0669 & 107 & -0.0833 & -0.1562 \\
406 & 0.0211 & 0.0662 & 201 & -0.1444 & -0.1468 \\
407 & 0.1153 & 0.1483 & 202 & -0.0467 & \\
409 & & 0.0174 & 203 & -0.0245 & -0.1288 \\
410 & & -0.0074 & 305 & 0.0527 & -0.1287 \\
412 & -0.2036 & -0.2074 & 501 & & 0.2001 \\
413 & -0.3024 & -0.2851 & 502 & & -0.2284 \\
414 & 0.246 & 0.2678 & 601 & 0.1759 & 0.0901 \\
415 & & -0.2177 & 602 & & -0.1463 \\
503 & & -0.308 & 603 & 0.0923 & -0.0012 \\
504 & -0.1978 & -0.1678 & 604 & & 0.0623 \\
505 & 0.2727 & 0.2454 & 605 & 0.0895 & -0.1289 \\
506 & -0.098 & -0.0813 & 606 & -0.0089 & -0.1694 \\
507 & & 0.1658 & 607 & & -0.2291 \\
701 & -0.2714 & -0.263 & 608 & & \\
702 & & 0.2414 & 705 & & \\
& & & 706 & & \\
\hline
\end{tabular}


TABLE A10. RESULTS OF EACH STAGE OF THE COMPONENT SELECTION PROCESS FOR THE ECONOMIC LEFTRIGHT SCALE. CORRELATIONS IN BOLD INDICATE COMPONENTS THAT WERE INCLUDED IN THE SCALE IN THAT ITERATION.

\begin{tabular}{|c|c|c|c|c|}
\hline \multirow[b]{2}{*}{ Component } & \multicolumn{4}{|c|}{ Iteration } \\
\hline & 1 & 2 & 3 & 4 \\
\hline 303 & 0.0648 & -0.0026 & -0.0308 & -0.0604 \\
\hline 401 & 0.3484 & 0.2923 & 0.3043 & 0.2915 \\
\hline 402 & 0.0626 & 0.0822 & 0.0386 & 0.0167 \\
\hline 403 & -0.0763 & -0.1157 & -0.1274 & -0.1508 \\
\hline 404 & -0.0483 & -0.0608 & -0.0568 & -0.0677 \\
\hline 405 & 0.0568 & 0.0195 & 0.0419 & 0.0368 \\
\hline 406 & 0.0159 & -0.0394 & -0.036 & -0.0459 \\
\hline 407 & 0.147 & 0.1629 & 0.1492 & 0.1369 \\
\hline 408 & -0.0092 & -0.032 & -0.0573 & -0.0722 \\
\hline 409 & -0.0101 & 0.0447 & 0.012 & 0.0252 \\
\hline 410 & 0.0121 & 0.0031 & -0.0404 & -0.0774 \\
\hline 411 & -0.0135 & -0.0665 & -0.1205 & -0.1246 \\
\hline 412 & -0.2048 & -0.2493 & -0.2345 & -0.2326 \\
\hline 413 & -0.2984 & -0.289 & -0.2921 & -0.2806 \\
\hline 414 & 0.2734 & 0.2312 & 0.2172 & 0.2038 \\
\hline 415 & -0.2413 & -0.1325 & -0.0849 & -0.042 \\
\hline 503 & -0.2898 & -0.3097 & -0.3409 & -0.3371 \\
\hline 504 & -0.0923 & -0.2145 & -0.266 & -0.2913 \\
\hline 505 & 0.2736 & 0.1947 & 0.217 & 0.2151 \\
\hline 506 & -0.0795 & -0.1004 & -0.1413 & -0.1726 \\
\hline 507 & 0.1698 & 0.2 & 0.2115 & 0.2273 \\
\hline 701 & -0.2459 & -0.2633 & -0.278 & -0.2751 \\
\hline 702 & 0.2585 & 0.2006 & 0.2302 & 0.2313 \\
\hline 108 & -0.0327 & -0.0661 & -0.0811 & -0.0969 \\
\hline 110 & -0.1136 & -0.1135 & -0.1079 & -0.1076 \\
\hline 301 & -0.0334 & -0.0858 & -0.1201 & -0.1404 \\
\hline 302 & 0.0903 & 0.0372 & 0.0352 & 0.0254 \\
\hline 416 & -0.1858 & -0.1749 & -0.1708 & -0.1762 \\
\hline 703 & 0.0413 & 0.007 & -0.0278 & -0.0561 \\
\hline 704 & -0.0451 & -0.0723 & -0.0679 & -0.07 \\
\hline 705 & -0.1412 & -0.1844 & -0.2035 & -0.2234 \\
\hline 706 & -0.1096 & -0.1614 & -0.1885 & -0.219 \\
\hline
\end{tabular}


TABLE A11. RESULTS OF EACH STAGE OF THE COMPONENT SELECTION PROCESS FOR THE SOCIAL LIBERALCONSERVATIVE SCALE. CORRELATIONS IN BOLD INDICATE COMPONENTS THAT WERE INCLUDED IN THE SCALE IN THAT ITERATION.

\begin{tabular}{|c|c|c|c|c|c|}
\hline Component & 1 & 2 & 3 & $\begin{array}{c}4 \\
\text { (cycle } \\
\text { break 1) }\end{array}$ & $\begin{array}{c}\mathbf{5} \\
\text { (cycle } \\
\text { break 2) } \\
\end{array}$ \\
\hline 101 & -0.0053 & -0.0109 & -0.001 & -0.011 & -0.0009 \\
\hline 102 & 0.0037 & -0.0015 & -0.0095 & -0.0017 & -0.0094 \\
\hline 103 & 0.0434 & 0.0686 & 0.0616 & 0.0695 & 0.0607 \\
\hline 104 & 0.039 & 0.0352 & 0.0279 & 0.0358 & 0.0274 \\
\hline 105 & -0.1623 & -0.1452 & -0.1473 & -0.1473 & -0.145 \\
\hline 106 & -0.1546 & -0.144 & -0.1352 & -0.1453 & -0.1338 \\
\hline 107 & -0.2442 & -0.2396 & -0.2533 & -0.2385 & -0.2539 \\
\hline 109 & 0.2037 & 0.2127 & 0.2194 & 0.2128 & 0.2192 \\
\hline 201 & -0.1347 & -0.1176 & -0.1261 & -0.119 & -0.1245 \\
\hline 202 & -0.1129 & -0.1184 & -0.1205 & -0.119 & -0.1197 \\
\hline 203 & 0.0306 & 0.0416 & 0.0553 & 0.0394 & 0.0574 \\
\hline 204 & 0.0808 & 0.1006 & 0.0904 & 0.0904 & 0.1006 \\
\hline 304 & 0.0668 & 0.0589 & 0.0563 & 0.0597 & 0.0553 \\
\hline 305 & 0.1268 & 0.1451 & 0.1535 & 0.1441 & 0.1545 \\
\hline 501 & -0.2216 & -0.2397 & -0.2522 & -0.2389 & -0.2527 \\
\hline 502 & -0.198 & -0.2112 & -0.2225 & -0.2101 & -0.2236 \\
\hline 601 & 0.1797 & 0.2096 & 0.2081 & 0.2099 & 0.2077 \\
\hline 602 & -0.0998 & -0.1525 & -0.0564 & -0.1525 & -0.0564 \\
\hline 603 & 0.0464 & 0.0329 & 0.032 & 0.0338 & 0.031 \\
\hline 604 & -0.0675 & -0.0806 & -0.0844 & -0.08 & -0.085 \\
\hline 605 & 0.0103 & -0.0206 & -0.0258 & -0.0198 & -0.0265 \\
\hline 606 & 0.0561 & 0.0439 & 0.0421 & 0.0438 & 0.0423 \\
\hline 607 & -0.1383 & -0.1624 & -0.1614 & -0.1662 & -0.1574 \\
\hline 608 & 0.1507 & 0.1712 & 0.1684 & 0.1728 & 0.1666 \\
\hline 108 & -0.0659 & -0.0864 & -0.0814 & -0.0859 & -0.0817 \\
\hline 110 & 0.0537 & 0.0696 & 0.069 & 0.0694 & 0.0692 \\
\hline 301 & -0.1821 & -0.1856 & -0.1816 & -0.1888 & -0.1776 \\
\hline 302 & 0.1212 & 0.1237 & 0.1109 & 0.1237 & 0.1109 \\
\hline 416 & -0.206 & -0.2119 & -0.218 & -0.2113 & -0.2186 \\
\hline 703 & -0.0393 & -0.0529 & -0.0561 & -0.0529 & -0.0561 \\
\hline 704 & -0.1124 & -0.1055 & -0.1079 & -0.1044 & -0.1089 \\
\hline 705 & -0.2124 & -0.2291 & -0.2354 & -0.2289 & -0.2355 \\
\hline 706 & -0.2498 & -0.2557 & -0.2653 & -0.2575 & -0.2635 \\
\hline
\end{tabular}


TABLE A12. CORRELATION BETWEEN THE ECONOMIC AND SOCIAL SCALES FOR ALL COUNTRIES IN THE MARPOR DATASET.

\begin{tabular}{|c|c|c|c|}
\hline Country & Correlation & Country & Correlation \\
\hline Albania & $0.3434 * *$ & Korea & 0.26 \\
\hline Armenia & $-0.0395+$ & Latvia & -0.1599 \\
\hline Australia & $0.204^{*}$ & Lithuania & 0.2326 \\
\hline Austria & -0.0738 & Luxembourg & $0.4297 * * *$ \\
\hline Azerbaijan & $0.1323+$ & Macedonia & -0.1903 \\
\hline Belarus & $0.1242+$ & Malta & $0.8484+$ \\
\hline Belgium & $0.1409 *$ & Mexico & -0.0365 \\
\hline Bosnia-Herzegovina & $0.3486 *$ & Moldova & -0.1606 \\
\hline Bulgaria & -0.1588 & Montenegro & $0.5199 * * *$ \\
\hline Canada & 0.0437 & Netherlands & $0.196 * *$ \\
\hline Croatia & 0.049 & New Zealand & $0.2898 * * *$ \\
\hline Cyprus & $-0.2862+$ & Northern Ireland & $0.3423 *$ \\
\hline Czech Republic & 0.0025 & Norway & $0.4208 * * *$ \\
\hline Denmark & $0.2426 * * *$ & Poland & $-0.3579 * * *$ \\
\hline Estonia & 0.1308 & Portugal & 0.1131 \\
\hline Finland & $0.2388 * * *$ & Romania & $0.3234^{* *}$ \\
\hline France & $0.3322 * * *$ & Russia & 0.0707 \\
\hline Georgia & -0.1178 & Serbia & 0.1186 \\
\hline $\begin{array}{c}\text { German Democratic } \\
\text { Republic }\end{array}$ & $0.1382 \dagger$ & Slovakia & -0.0389 \\
\hline Germany & $0.2733 * *$ & Slovenia & $0.4234 * * *$ \\
\hline Great Britain & $0.2284^{*}$ & Spain & -0.0352 \\
\hline Greece & $0.2766^{*}$ & Sri Lanka & $0.4018+$ \\
\hline Hungary & $-0.2762 *$ & Sweden & $0.2071^{* *}$ \\
\hline Iceland & $0.4608^{* * *}$ & Switzerland & $0.4683^{* * *}$ \\
\hline Ireland & $0.3833^{* * *}$ & Turkey & 0.0975 \\
\hline Israel & $0.2509 * * *$ & Ukraine & $-0.4013 * * *$ \\
\hline Italy & $0.4248^{* * *}$ & United States & 0.1994 \\
\hline Japan & $0.2363 * *$ & & \\
\hline
\end{tabular}

tLow number of observations in MARPOR dataset $(<20)$, interpret correlation/(lack of) significance with caution. 